\title{
MAGMATISMO PÓS-TECTÔNICO INVESTIGADO POR MEIO DOS MÉTODOS GEOCRONOLÓGICOS U-Pb E Lu-Hf, COMPLEXO PEDRA BRANCA, RIO DE JANEIRO - RJ
}

\author{
POST TECTONIC MAGMATISM INVESTIGATED BY U-Pb AND Lu-Hf GEOCHRONOLOGICAL \\ METHODS, PEDRA BRANCA COMPLEX, RIO DE JANEIRO-RJ
} \author{
GERALDES $^{1}$, Maria Virgínia Alves MARTINS ${ }^{1}$ \\ E-mails: carolmoterani@gmail.com; mauro.geraldes@gmail.com; virginia.martins@ua.pt

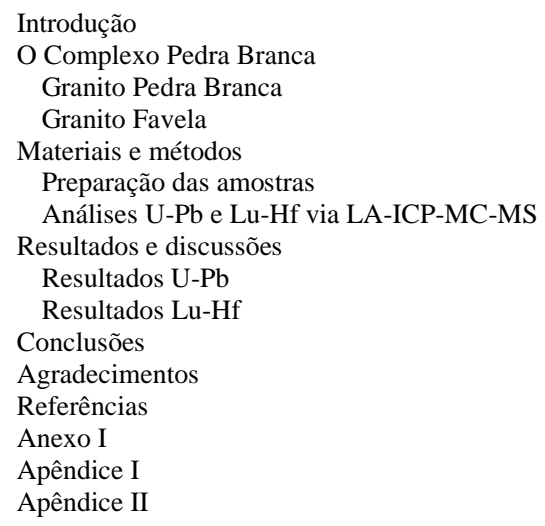

Ana Carolina Machado MOTERANI ${ }^{1}$, Rubem PORTO JÚNIOR ${ }^{2}$, Mauro Cesar

${ }^{1}$ Universidade do Estado do Rio de Janeiro. Rua São Francisco Xavier, 524, Maracanã, Rio de Janeiro, Rio de Janeiro.

22Universidade Federal Rural do Rio de Janeiro. BR-465, Km 7. Seropédica, Rio de Janeiro. E-mail: rubempjr@gmail.com

RESUMO - O Complexo Pedra Branca (CPB) está localizado na zona oeste da cidade do Rio de Janeiro (SE Brasil) e está inserido tectonicamente no Domínio Costeiro, pertencente ao Terreno Oriental da Faixa Ribeira Central. Os litotipos que formam o CPB foram gerados em eventos relacionados à Orogênese Brasiliana ( 600 Ma), abrigando assim rochas pré- a pós-colisionais. Estudos anteriores de corpos graníticos pós-tectônicos na Faixa Ribeira revelaram que o magmatismo ocorreu em dois pulsos distintos, com intervalo de aproximadamente $30 \mathrm{Ma}$ entre eles. O presente estudo analisou 9 amostras do CPB, através dos métodos geocronológicos U-Pb e LuHf via LA-ICP-MC-MS, referentes às litologias granito Pedra Branca e granito Favela, possíveis representantes do pulso mais antigo e mais jovem, respectivamente, buscando melhorar a compreensão do magmatismo pós-tectônico na região. As médias das idades encontradas para o granito Pedra Branca ( $509 \pm 5 \mathrm{Ma}$ ) e granito Favela (489 $\pm 6 \mathrm{Ma}$ ) corroboraram com os valores descritos na literatura e indicaram que o magmatismo ocorrido no CPB teve origem na forma de pulsos progressivos, porém num intervalo de tempo menor ( $20 \mathrm{Ma}$ ) do que foi anteriormente determinado. O indicador petrogenético $\mathrm{HHf}$ indicou participação de fontes crustais e mantélicas, dando caráter bimodal ao magmatismo registrado no CPB.

Palavras-chave: Geocronologia. Magmatismo. Isótopos. LA-MC-ICP-MS. Zircão.

\begin{abstract}
The Pedra Branca Complex is located at the western region of the Rio de Janeiro city (SE Brazil). Tectonically it is inserted in the Coastal Domain, which is part of the central segment of the Ribeira Belt. The lithologies that formed this rocky complex were generated in events related to the Brasiliano Orogeny ( $\sim 600 \mathrm{Ma}$ ), thus contains pre- to- post-collisional rocks. Previous studies on post-tectonic granite bodies belonging to Ribeira belt revealed that the magmatism occurred in two distinct pulses, with an interval of approximately 30 Ma between them. The present study analyzed 9 CPB samples, using the U-Pb and Lu-Hf through LA-ICP-MCMS geochronological methods, with focus on the Pedra Branca granite and Favela granite, which may represent the older and the younger pulses respectively, in order to improve the understanding of the post-tectonic magmatism in the area. The average ages found for the Pedra Branca (509 $\pm 5 \mathrm{Ma}$ ) and Favela (489 $\pm 6 \mathrm{Ma}$ ) granites confirm the previously described ages in the literature. However, they indicate that the magmatism in CPB occurred in the form of progressive pulses, with an interval between both events of $\sim 20 \mathrm{Ma}$, that is, less than what was previously estimated (of $~ 30 \mathrm{Ma}$ ). In addition, the petrogenetic indicator $\varepsilon$ Hf indicated the participation of crustal and mantle sources, which gives a bimodal character to the magmatism registered in the CPB.
\end{abstract}

Keywords: Geochronology; Magmatism; Isotopes; LA-ICP-MC-MS; Zircon.

\section{INTRODUÇÃO}

O Maciço da Pedra Branca é uma importante feição fisiográfica da cidade do Rio de Janeiro. Ele possui o ponto mais alto da cidade e mais de 80\% de sua área está localizada no Parque Estadual com o mesmo nome (Porto Jr., 2004).
As rochas pertencentes a este complexo rochoso estão relacionadas à evolução geotectônica do Segmento Central da Faixa Ribeira. Esta estrutura foi formada durante a amalgamação do Supercontinente Gondwana que foi responsável 
pela formação de diversos corpos graníticos (Almeida et al., 1973; Valeriano et al., 2011, 2016), onde os que apresentam um caráter póstectônico estão localizados em uma faixa de 400 km (Almeida et al., 1973; Valeriano et al., 2011, 2016). Valeriano et al. (2011) reforça a premissa de que o magmatismo pós-tectônico na área ocorreu em dois pulsos magmáticos distintos: um anterior, Cambriano, com idade média de 513 Ma, responsável pela geração dos granitos Pedra Branca, Suruí e Buarama, e outro Ordoviciano, mais recente, com idade média de $486 \mathrm{Ma}$, formador dos granitos Mangaratiba, Favela, Frades, Nova Friburgo e Sana.

A utilização conjunta dos métodos geocronológicos U-Pb e Lu-Hf em grãos de zircão possibilita a obtenção de idades e razões isotópicas precisas, que permitem entender a geração e evolução dos diferentes corpos rochosos (Harley et al., 2007; Bertotti et al., 2013; Nebel et al., 2007, 2014).

O presente trabalho tem como objetivo contri- buir para uma melhor compreensão do magmatismo, que deu lugar à formação dos granitos Pedra Branca e Favela. Ambos pertencem ao Maciço Pedra Branca e representam distintos eventos magmáticos: um ordoviciano (o granito Pedra Branca) e o outro cambriano (granito Favela). Além disso, ele pretende também obter informações a respeito da fonte do magmatismo.

\section{O Complexo Pedra Branca}

O Complexo Pedra Branca (CPB, Figura 1 Porto Jr, 1993) está inserido no contexto geológico da evolução do Segmento Central da Faixa Ribeira, que corresponde parcialmente ao Cinturão Móvel Ribeira (Almeida et al., 1973) ou à porção central da Província Mantiqueira (Hasui \& Oliveira, 1984). A Faixa Ribeira (Almeida et al., 1973) foi formada durante diversos processos de colisão que ocorreram durante a orogenia Brasiliana-Pan-Africana, entre os períodos Ediacarano ao Cambriano (Heilbron \& Machado 2003; Valeriano et al. 2011).

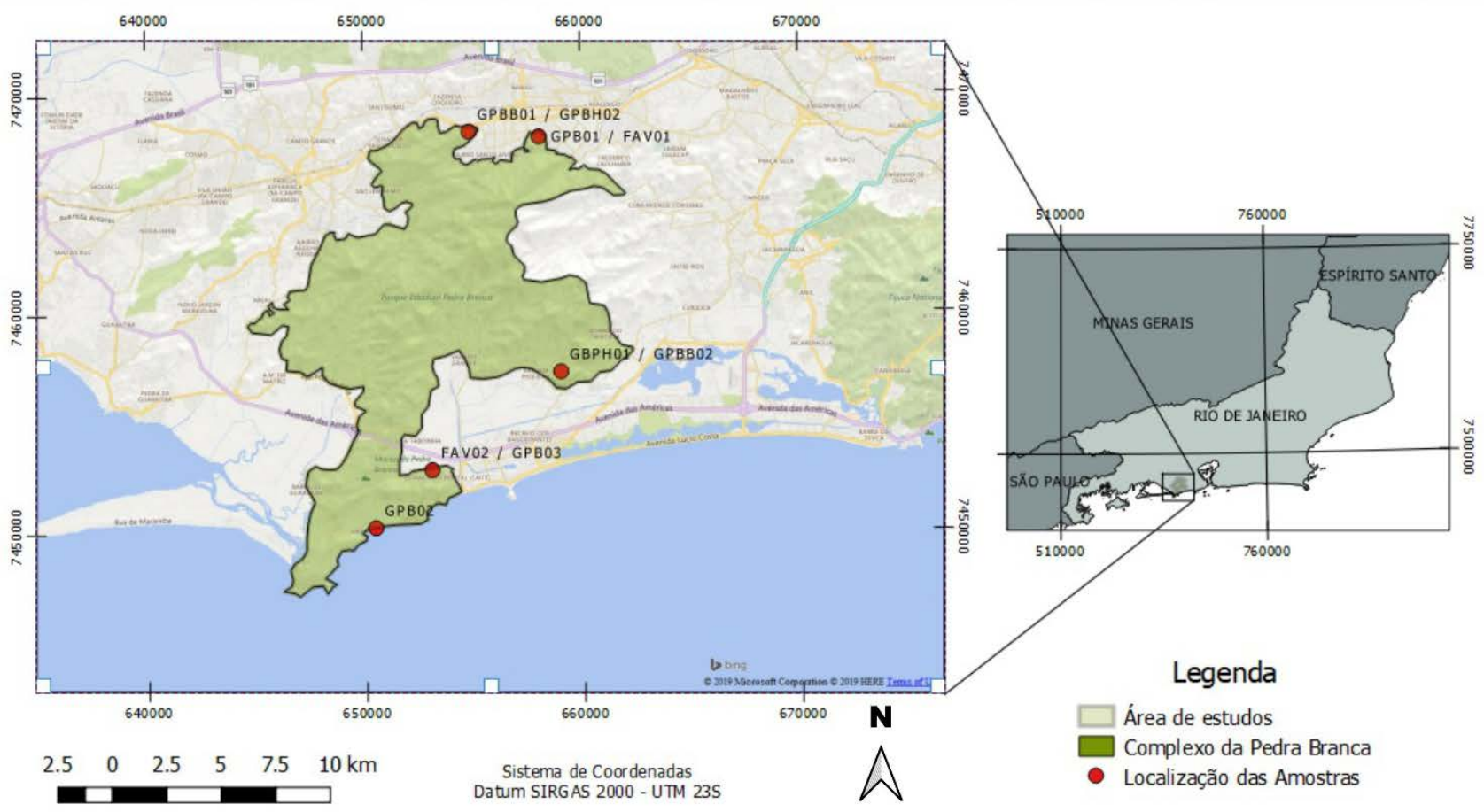

Figura 1: Complexo Pedra Branca delimitado em mapa, com a localização e identificação das amostras coletadas.

A compartimentação da Faixa Ribeira é dada por quatro terrenos tectono-estratigráficos: Ocidental, que corresponde à margem retrabalhada do Cráton São Francisco, Terreno Paraíba do Sul, Terreno Oriental e Terreno Cabo Frio (Heilbron et al. 2000, 2004; Trouw et al. 2000; Tupinambá et al., 2007). Estes estão imbricados em direção ao Cráton São Francisco, no sentido NW/W. Entre 860-620 Ma ocorreu um longo período de subducção para oeste, que resultou na geração de arcos como o arco Rio Negro, Cambuci, Guanabara e serra da Bolívia (Tupinambá et al., 2000, 2013; Porto Jr. 2004; Heilbron et al., 2013; Valeriano et al., 2016). Durante 620-605 Ma ocorreu a colisão entre a margem do Cráton São Francisco com o microcontinente Paraíba do Sul - Embu (Trouw et al., 2013; Valeriano et al., 2016). A principal colisão 
registrada no cinturão Ribeira ocorreu com a acreção do Terreno Oriental, entre 605-550 Ma, onde foram gerados granitoides foliados com composição metaluminosa a peraluminosa e granitos híbridos (Heilbron \& Machado, 2003; Valeriano et al., 2016). A última colisão se iniciou há 530 Ma, com a acreção do Terreno Cabo Frio no Terreno Oriental e, por fim, foram formados granitos pós tectônicos, relacionados à tectônica gerada pelo colapso do orógeno entre 513-480 Ma (Heilbron \& Machado, 2003).

De acordo com Heilbron \& Machado (2003), o Terreno Oriental é divido em três diferentes domínios: Cambuci, Costeiro e Klippe de Italva. O Domínio Cambuci compreende o embasamento deste terreno além de uma sucessão de rochas metassedimentares sobrepostas ao embasamento. Litologicamente, o embasamento é formado por granada-horneblenda-biotita tonalitos, charnokitos, dioritos e granitos porfiríticos, enquanto as sucessões são formadas por silimanita-granada-biotita gnaisses, com camadas de mármore dolomítico e poucas lentes de rochas calcissilicáticas, gonditos e anfibolitos (Heilbron \& Machado, 2003). O Domínio Costeiro, onde a região deste trabalho está inserida, é formado por duas associações metassedimentares que são intrudidas pelo Arco Magmático Rio Negro (Tupinambá et al., 1996) e por diversas gerações de granitoides de idade mais recente.

O CPB apresenta uma área de aproximadamente $160 \mathrm{Km}^{2}$ e foi definido por Porto Jr (1993) a partir do desenvolvimento de estudos na área feitos por diversos autores, onde se destacam os trabalhos de Helmbold et al. (1965), Penha (1984), Penha \& Wiedemann (1984), Porto \& Valente (1988), Porto Jr. \& Esteves (2001) e Esteves (2002). A complementação de dados feita por Porto Jr. (1993, 1994) permitiu a caracterização e individualização dos conjuntos de rochas na área em três principais unidades (Tonalítica (Utn), Granito Pedra Branca (Ugpb) e Biotita Granito (Ubg) como também a definição de quatro fácies referentes ao granito Pedra Branca (Média-Homogênea, Bandada, Pegmatítica e Hololeucocrática). Estas três unidades, somadas às rochas encaixantes, que são definidas por uma sequência ortoderivada (Série Inferior) e por outra paraderivada (Série Superior), formam o CPB (Porto Jr., 2004).

\section{Granito Pedra Branca}

O granito Pedra Branca (GPB) é um granito porfirítico, enriquecido em megacristais de micro- clínio pertítico, que se sobressaem em matriz de composição monzogranítica. Os megacristais de microclínio apresentam-se orientados de forma planar e/ou linear, o que confere à rocha uma foliação e lineação classificadas por Penha \& Wiedemman (1984), Porto Jr. \& Valente (1988) e Porto Jr. (1994, 2004) como primárias e de origem relacionada a fluxo magmático (Porto Jr., 2004). O granito Pedra Branca pode ser visualizado na forma de grandes paredões de rochas cruas ou em forma de matacões. Quatro fácies foram individualizadas: Média-Homogênea (Figura 2a), Bandada (Figura 2b), Pegmatítica e Hololeucocrática (Figura 2c) (Porto Jr., 2004). A fácies Média-Homogênea (Porto Jr. \& Valente, 1988) é a dominante em área. Pode ser visualizada na pedreira EMASA, em Campo Grande, no Morro do Sandá, localizado mais a norte do Maciço, além da Pedra do Calembá, em Vargem Grande e o Morro de Grumari, no Recreio dos Bandeirantes. A rocha apresenta megacristais de microclínio pertítico, em que o tamanho do grão varia de 2 a $4 \mathrm{~cm}$. Os megacristais estão envoltos por matriz de granulometria média, rica em quartzo, plagioclásio e microclínio (Porto Jr., 2004). A fácies Bandada (Porto Jr. 1993), apesar de ser a segunda em relação à área de ocorrência, possui difícil individualização em mapas com escalas menores que 1:10.000, devido à dificuldade de visualização de seu bandamento característico, que é formado em função do hábito colunar que os megacristais de (microclínio) adquirem e seu alinhamento por fluxo. Este bandamento é realçado pela presença de filetes de biotita que se encontram alinhados de acordo com planos definidos pelo posicionamento dos megacristais. A origem destes filetes pode estar relacionada a enclaves microgranulares ou xenolíticos muito assimilados ou "schlierens" de biotita, que se formam em função do fluxo magmático (Porto Jr., 1994, 2004). A fácies Pegmatítica (Porto Jr. \& Valente, 1988) ocorre na sequência do contato da intrusão granítica com a rocha encaixante, na forma de diques e/ou bolsões pegmatíticos e só pode ser individualizada em perfis de pedreiras, sendo a Pedreira Bangu a área onde foi definida. Composicionalmente, possui 75\% de seu volume composto por cristais centimétricos (até $12 \mathrm{~cm}$ ) de microclínio pertítico, com matriz grossa contendo quartzo, plagioclásio albítico e rara biotita (Porto Jr., 2004). A fácies Hololeucocrática utiliza a fácies Média-Homogênea como 
hospedeira e, assim, se apresenta na forma de bandas interestratificadas, homogêneas, de 5 a 60 cm de espessura, que são contrastantes com a Média-Homogênea. Devido a isto, é a que ocorre de forma mais restrita em relação à área, aflorando principalmente nas pedreiras EMASA e IBRATA. Possui cor branca, textura equigranular, com grãos de microclínio, plagioclásio, quartzo e rara magnetita. Há presença de fluxo, que se torna mais visível devido à constante intercalação entre as duas fácies. Não é possível visualizar estruturas de bordas resfriadas durante as intercalações e, somado à forma e geometria
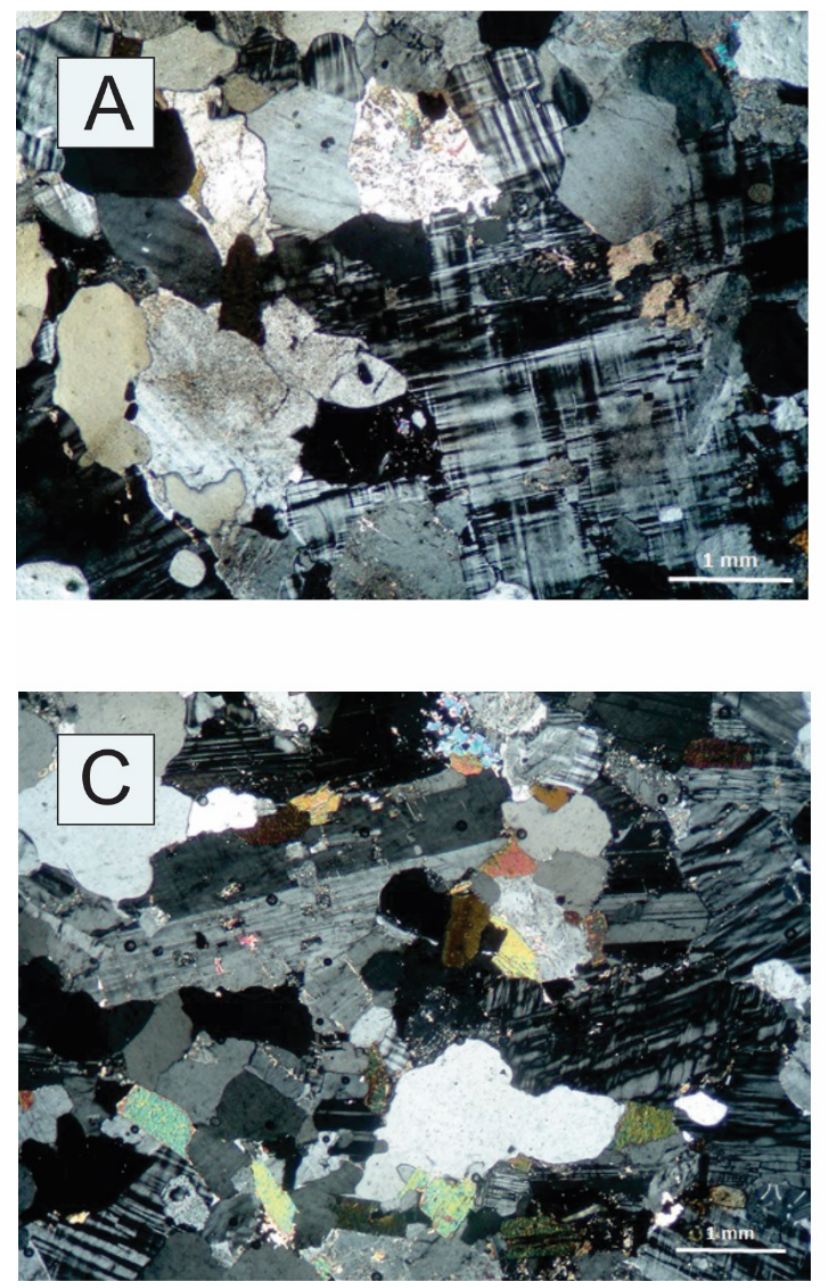

das bandas, é possível perceber que não há grande variação de temperatura entre estas (Porto Jr. et al., 1992a e b, 1993; Porto Jr., 2004). Com exceção deste contato formado entre as fácies Hololeucocrática e Média-Homogênea, os outros contatos presentes no granito Pedra Branca ocorrem quase totalmente na forma gradacional, o que pode ser explicado como sendo fruto de uma cristalização que ocorreu num período relativamente curto, com presença de um fluxo de "magmas" que possuíam diferentes mobilidades dentro da mesma câmara magmática (Porto Jr., 2004).
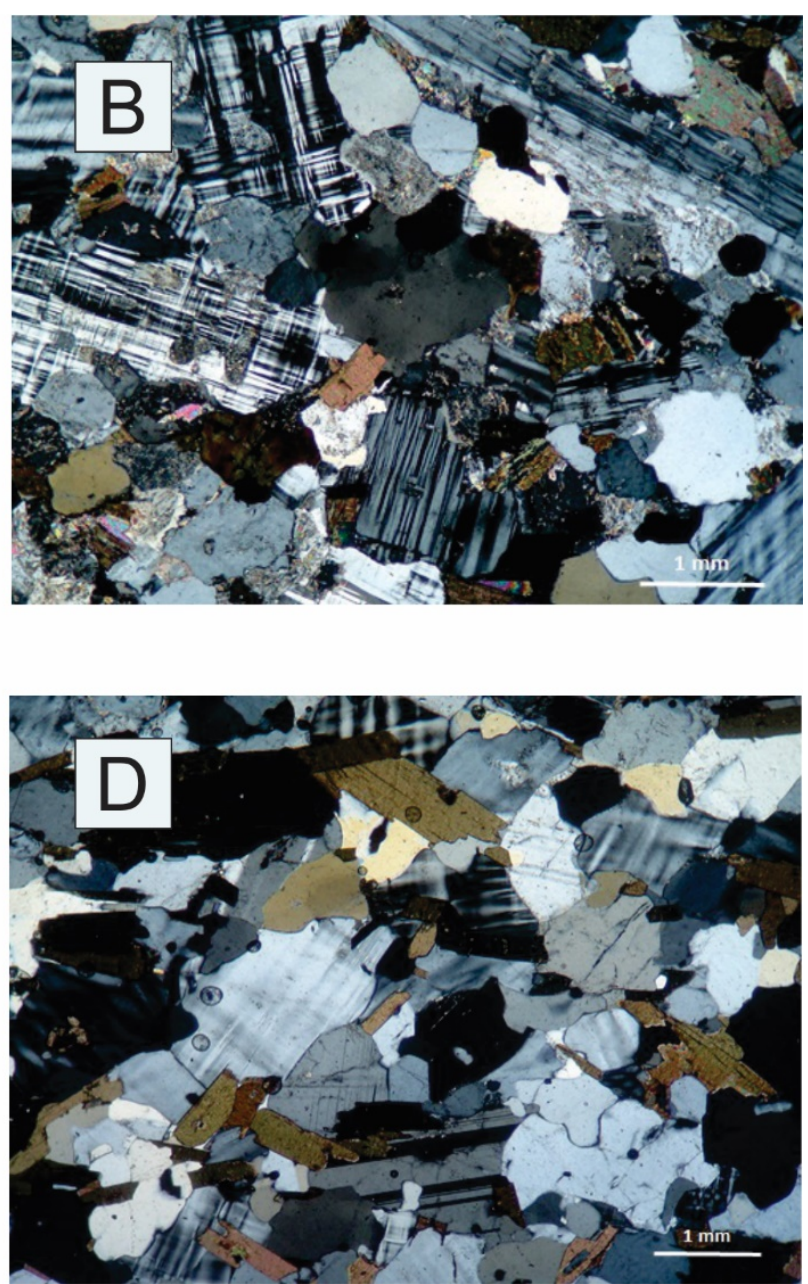

Figura 2: Fotomicrografias referentes à litologia de cada amostra analisada neste trabalho. a) Referente à fácies MédiaHomogênea do GPB. b) Referente à fácies Bandada do GPB. c) Referente à fácies Hololeucocrática do GPB. d) Granito Favela.

Porto Jr. (2004) e Porto Jr. et al. (2018) propõem uma interpretação para a origem do acamamento magmático formado pelas fácies Hololeucocrática e Média-Homogênea (Figura 3a e b) baseado em um modelo análogo para magmas silicosos proposto inicialmente por Vigneresse et al. (1996). O processo seria resultado de efeitos combinados de cristalização in situ e percolação por filter pressing (Mckenzie, 1987) de líquido intersticial para zonas de baixo gradiente de pressão. O processo inicial deu-se por cristalização fracionada, onde o líquido possuía de $20 \%$ a $55 \%$ de cristais formados, permitindo que estes rotacionassem livremente segundo um fluxo magmático. Próximo ao limite de 55\% definiu-se o limite de percolação rígida (Rigid Percolation Threshold $R P T)$. Neste estágio, boa parte dos minerais acessórios e opacos precoces se cristalizaram, empobrecendo o líquido nestes. Acima do limite 
RPT, até o limite de bloqueio de partículas (Particle Locking Threshold - PLT), onde aproximadamente 72 a $75 \%$ do material estava cristalizado, a interação mecânica entre as partículas sólidas foi intensa devido ao stress causado pelas tensões diapíricas e ascensão do magma, forçando, então, o líquido intersticial a fluir para zonas com menor pressão. Esta percolação ocorreu preferencialmente em zonas de borda da intrusão com limitações devido à permeabilidade do crystal mush e do aumento

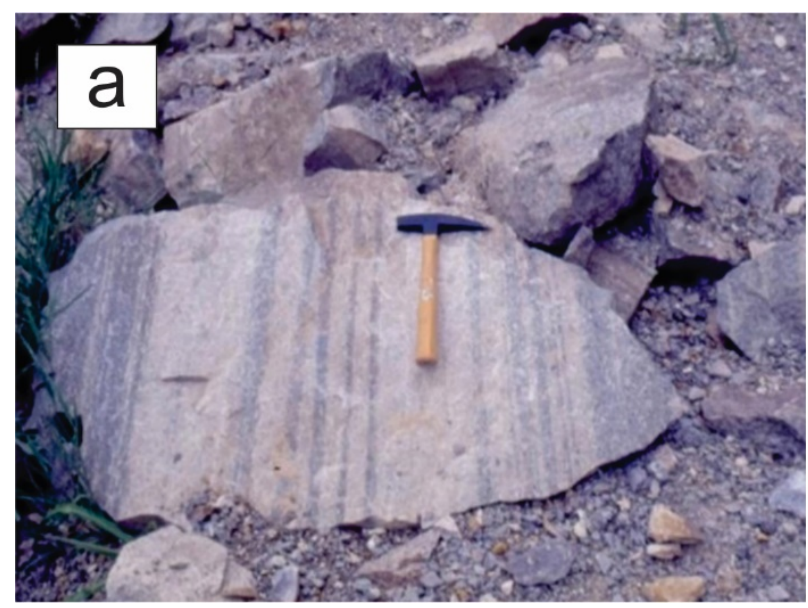

da componente de cisalhamento nessas regiões. O líquido residual, com composição muito próxima ao eutético granítico, então se depositou nas regiões de baixas pressões $(\sigma 3)$, onde cristalizou. Sendo assim, a formação da fácies Hololeucocrática se deu através dos processos cumuláticos relacionados ao fluxo do magma próximo à encaixante somado com a percolação do líquido intersticial por filter pressing (Mckenzie, 1987; Porto Jr. et al., 2018).

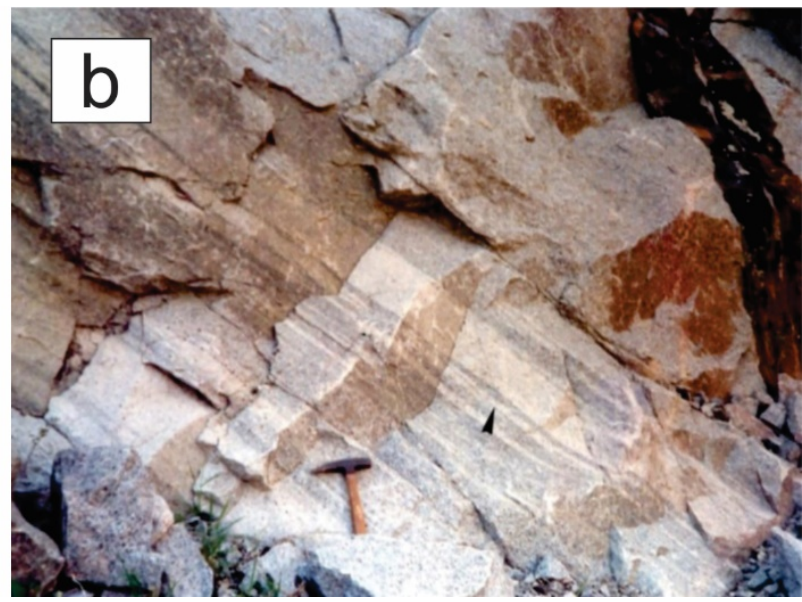

Figura 3: a) e b) Padrão do acamamento magmático do GPB vistos em afloramento, formado pelas fácies Hololeucocrática (mais claras) e Média-Homogênea (mais escuras).

\section{Granito Favela}

De acordo com Pires et al. (1982), o Granito Favela (Figura 2d) possui cor cinza, é isotrópico e pode variar texturalmente de equigranular a porfirítico e é caracterizado pela presença de uma fácies equigranular, uma fácies porfirítica e uma fácies glomeroporfirítica. Segundo os referidos autores, a fácies equigranular é rica em microclínio, plagioclásio e biotita e possui allanita, titanita, zircão, apatita e minerais opacos como acessórios. Esta fácies não possui enclaves e nem megacristais. Na fácies porfirítica é possível visualizar a estrutura de fluxo através do alinhamento de alguns cristais de microclínio que se encontram dispersos em matriz equigranular média. Esta fácies possui enclaves microgranulares mesocráticos. A fácies glomeroporfirítica é semelhante à fácies porfirítica, mas apresenta enriquecimento em allanita. A mudança de textura se dá pela presença de aglomerados esbranquiçados de quartzo e plagioclásio que, realçados pela matriz, geram uma textura glomeroporfirítica. A visualização desta rocha em mapas com escalas menores que 1:10.000 é muito difícil. Boas ocorrências podem ser visualizadas nas regiões do Morro do Sandá, do Pontal e Barra de Guaratiba. A fácies glomeroporfirítica aflora com boa exposição na região da Pedra da Rosilha, tendo sido, localmente, denominado de granodiorito Rosilha (Porto Jr., 2004).

\section{MATERIAIS E MÉTODOS}

Para execução deste trabalho foram coletadas 9 amostras, de diferentes setores do Complexo, procurando-se obter uma amostragem representativa da área de estudo: 3 amostras referentes à fácies Média-Homogênea do GPB, 2 à fácies Bandada, 2 à fácies Hololeucocrática e 2 ao Granito Favela. Todas as amostras foram utilizadas para obtenção de idades pelo método U-Pb e 6 foram selecionadas para análise pelo método Lu-Hf: 2 representantes da fácies Média-Homo- gênea do GPB, 1 da fácies Bandada, 1 da fácies Hololeucocrática e 2 do granito Favela. A Tabela 1 resume a tipologia, o local de coleta e os métodos geocronológicos que foram empregados para cada amostra.

\section{Preparação de amostras}

As amostras foram preparadas a fim de separar grãos de zircão, onde foram feitas datações geocronológicas via LA-ICP-MC-MS (Laser Ablation - Ion Coupled Plasma - 
Multicollector - Mass Spectrometer). Todo o processo de preparação foi realizado no Laboratório Geológico de Preparação de Amostras (LGPA), na Universidade do Estado do Rio de Janeiro, UERJ.

Os processos de preparação envolveram cominuição e moagem, através de moinho britador e de disco, separação de minerais pesados, por bateia, mesa vibratória e líquidos densos e, por fim, separação magnética pelo separador Frantz, onde as últimas frações foram coletadas. Os grãos selecionados foram distribuídos em grupos de acordo com sua suscetibilidade magnética e adicionados a uma resina epóxi. Nesta resina são polidos para obter a maior área possível de contato.

\section{Análises U-Pb e Lu-Hf via LA-ICP-MC-MS}

Os epóxis contendo os grãos foram imageados por Microscópio Eletrônico de Varredura (MEV) e as imagens funcionaram como mapa para escolha dos grãos que receberam os tiros de laser (Anexo 1). O tiro a laser volatiliza e conduz a amostra ao plasma (gás argônio) que é aquecido em altas temperaturas (8000k), causando a ionização das moléculas, que são então conduzidas ao espectrômetro de massa para leitura dos elementos em detectores do tipo Faraday e Multiplicadores de Elétrons. A metodologia para ambas as análises (U-Pb e Lu-Hf) envolve a análise de dois brancos, para descartar contaminação, além da calibração do aparelho com base nos padrões existentes, como GJ-01 e 91500 (para U-Pb) e GJ-01, 91500 e MudTank (para Lu-Hf). Os resultados gerados foram refinados e utilizados na confecção de diagramas concórdia através da extensão IsoPlot 4.15 (Ludwig, 2012), para obtenção das idades U-Pb e os indicadores $\varepsilon \mathrm{Hf}$ fornecidos indicaram a possível rocha fonte do magmatismo. Este processo foi realizado no MULTILAB - UERJ. Para os cálculos de Lu-Hf, o valor da constante de decaimento do ${ }^{176} \mathrm{Lu}$ foi de $1,867 \times 10^{-11} / \mathrm{ano}$, definida por Söderlund et al. (2004). Os valores utilizados de condrito para as razões ${ }^{176} \mathrm{Hf} /{ }^{177} \mathrm{Hf}=0.0336$ e ${ }^{176} \mathrm{Lu} /{ }^{177} \mathrm{Hf}=0.282785$ foram definidas por Bouvier et al. (2008). O modelo de manto depletado em relação aos dias atuais utiliza os valores 0,28325 para a razão ${ }^{176} \mathrm{Hf} /{ }^{177} \mathrm{Hf}$ e 0,0388 para ${ }^{176} \mathrm{Lu} /{ }^{177} \mathrm{Hf}$, definido por Griffin et al. (2000) e atualizado por Andersen et al. (2009).

Tabela 1: Caracterização das amostras coletadas em relação ao seu código, tipo, local de coleta, setor no maciço e método geocronológico utilizado.

\begin{tabular}{|c|c|c|c|c|c|}
\hline Amostra & Litologia & Faciologia & $\begin{array}{c}\text { Local } \\
\text { Amostrado }\end{array}$ & $\begin{array}{c}\text { Setor do } \\
\text { Maciço }\end{array}$ & $\begin{array}{c}\text { Método } \\
\text { Geocronológico }\end{array}$ \\
\hline GPB01 & Granito Pedra Branca & Fácies Média-Homogênea & Pedreira Bangu & Norte & U-Pb e Lu-Hf \\
\hline GPB02 & Granito Pedra Branca & Fácies Média-Homogênea & $\begin{array}{l}\text { Av. Estado da } \\
\text { Guanabara }\end{array}$ & Sul & U-Pb e Lu-Hf \\
\hline GPB03 & Granito Pedra Branca & Fácies Média-Homogênea & Estrada do Pontal & Sul & $\mathrm{U}-\mathrm{Pb}$ \\
\hline GPBB01 & Granito Pedra Branca & Fácies Bandada & Pedreira JABOUR & Norte & $\mathrm{U}-\mathrm{Pb}$ \\
\hline GPBB02 & Granito Pedra Branca & Fácies Bandada & Pedreira IBRATA & Sul & U-Pb e Lu-Hf \\
\hline GPBH01 & Granito Pedra Branca & Fácies Hololeucocrática & Pedreira IBRATA & Sul & $\mathrm{U}-\mathrm{Pb}$ \\
\hline GPBH02 & Granito Pedra Branca & Fácies Hololeucocrática & Pedreira JABOUR & Norte & U-Pb e Lu-Hf \\
\hline FAV01 & Granito Favela & & Pedreira Bangu & Norte & U-Pb e Lu-Hf \\
\hline FAV02 & Granito Favela & & Estrada do Pontal & Sul & U-Pb e Lu-Hf \\
\hline
\end{tabular}

\section{RESULTADOS E DISCUSSÃO}

As idades U-Pb de cada amostra foram geradas a partir de diagramas concórdia (Figura 4). Os dados referentes aos grãos que foram utilizados para confecção de cada diagrama encontram-se especificados no apêndice I.

Com o intuito de identificar os dois principais 

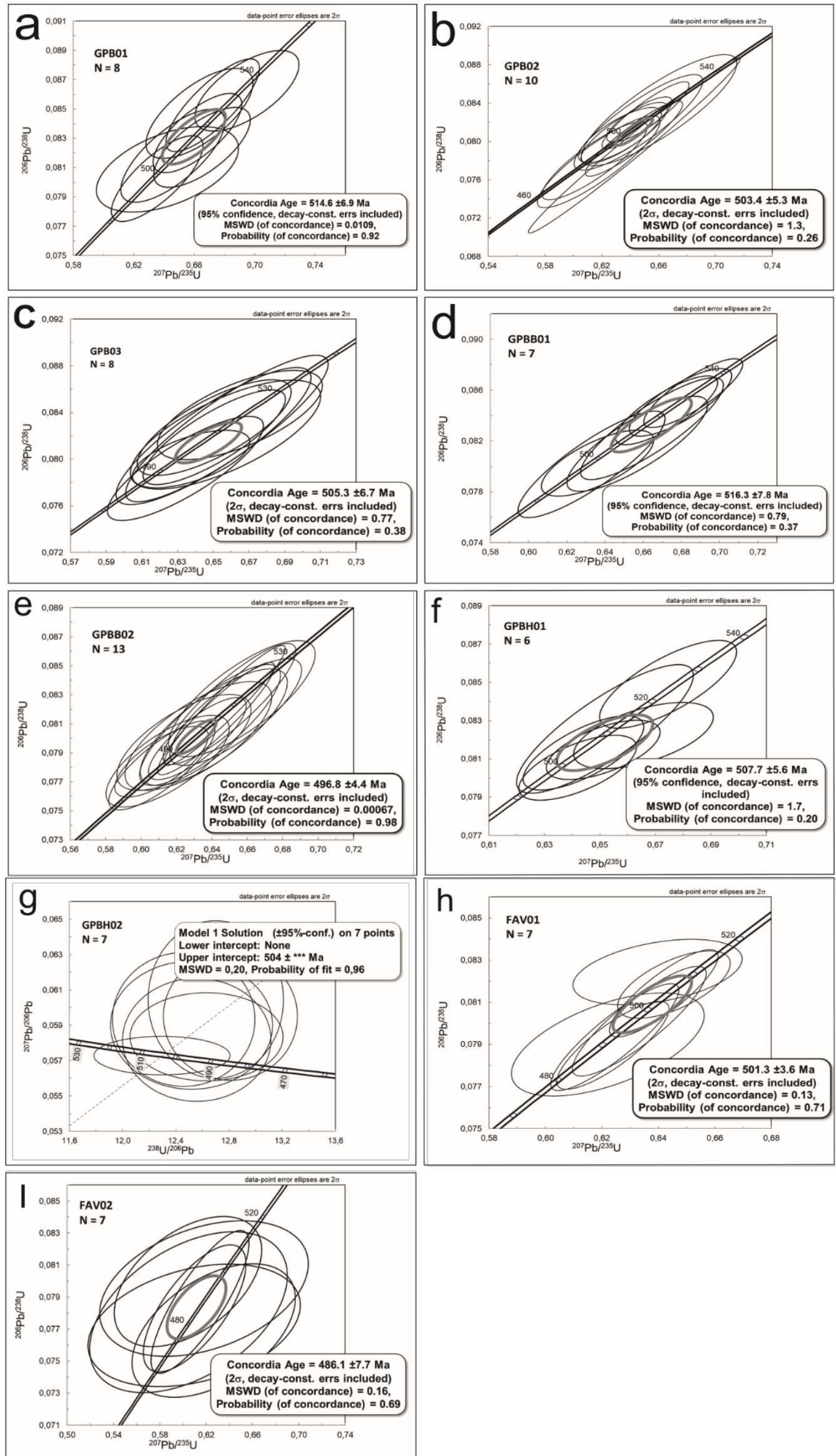

Figura 4: Diagramas concórdia gerados para cada amostra estudada e suas respectivas idades, onde "N" indica o número de grãos datados utilizados para confecção do diagrama. a) Amostra GPB01, com idade 514,6 \pm 6,9 Ma; b) GPB02 com idade 503,4 \pm 5,3 Ma; c) GPB03 com idade 505,3 \pm 6,7 Ma; d) GPBB01 com idade 516,3 \pm 7,8 Ma; e) GPBB02 com idade 496,8 \pm 4,4 Ma; f) GPBH01 com idade 507,7 \pm 5,6 Ma; g) GPBH02 com idade 504 Ma; h) FAV01 com idade 501 \pm 3,6 Ma; i) FAV02 $486 \pm$ 7,7 Ma. 
pulsos magmáticos inseridos na área do Complexo Pedra Branca foi estimada a média ponderada das idades isocrônicas U-Pb acima de 500 Ma e abaixo de 500 Ma. A figura 5 compara as médias encontradas por este trabalho e por Valeriano et al. (2011). Todas as idades foram obtidas por meio do método geocronológico U$\mathrm{Pb}$.

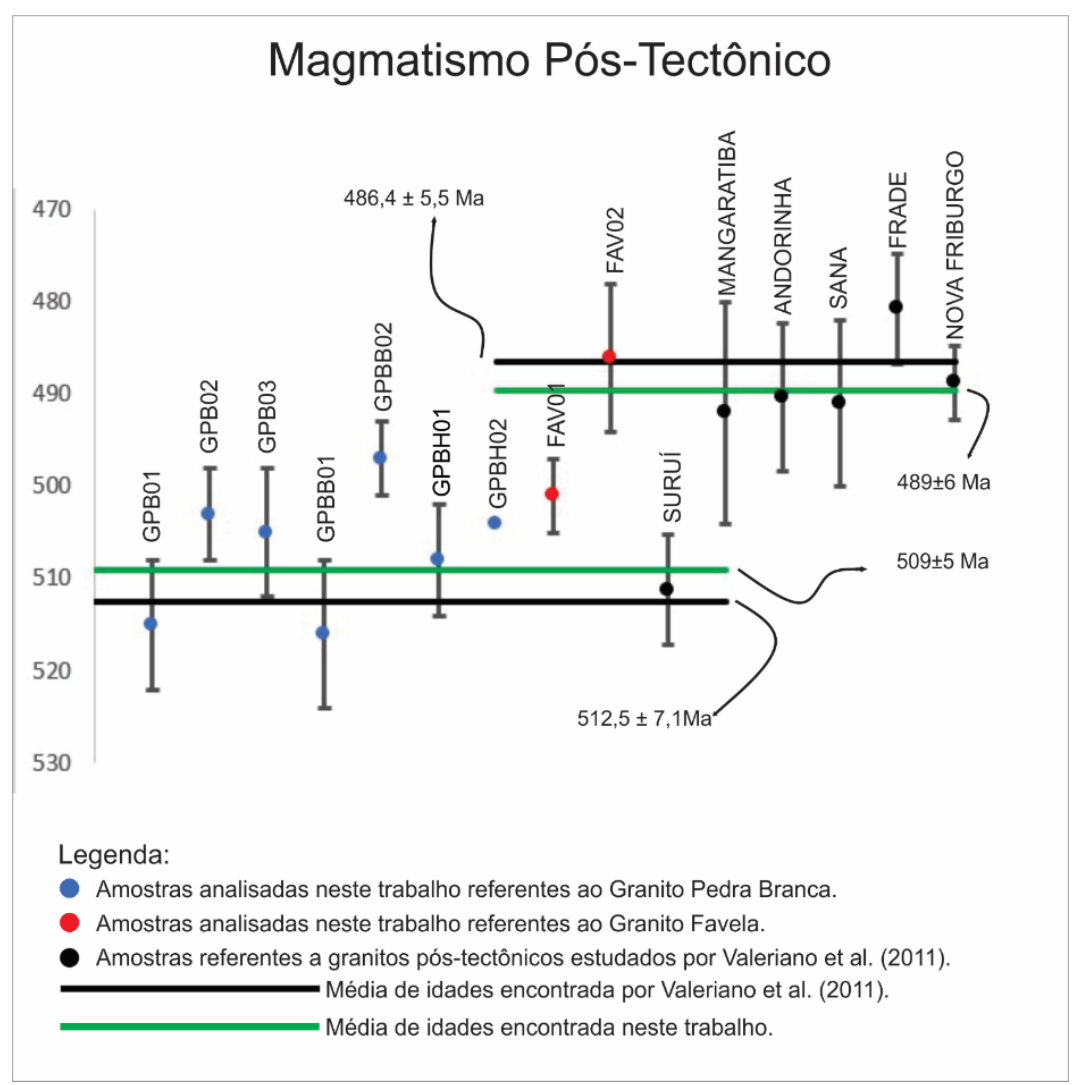

Figura 5: Comparação entre idades U-Pb e correspondentes médias ponderadas, obtidas no presente trabalho para os granitos Pedra Branca e Favela, e as obtidas por Valeriano et al. (2011), para outros granitos pós-tectônicos da parte central da Faixa Ribeira.

É possível inferir que 7 (dentre as 9) amostras analisadas indicaram idades correspondentes às esperadas para suas respectivas litologias, com exceção da amostra GPBB02 (496,8 \pm 4,4 Ma), referente ao granito Pedra Branca, e a amostra FAV01 (501 \pm 3,6 Ma), referente ao granito Favela. Estas idades podem indicar que a atividade magmática no Complexo Pedra Branca tenha ocorrido de forma progressiva. O valor médio calculado para o intervalo entre as atividades magmáticas diminuiu de $\sim 30$ Ma para $\sim 20 \mathrm{Ma}$, o que também corrobora com esta hipótese.

Os valores encontrados para as fácies Hololeucocrática e Média Homogênea se mostraram alternados e próximos, confirmando a cogeneticidade discutida por Porto Jr. (2004) e Porto Jr. et al. (2018) em relação à interdigitação formada entre elas (Figura 6).

De forma majoritária, foi possível notar que a região norte do maciço abriga as amostras que apresentaram idades mais antigas (Figura 6), podendo indicar que a geração de magma ocorreu

na forma de pulsos. Registre-se que a forma de emplacement relacionada a estas intrusões é do tipo "dique/sill”, formando diques e soleiras espalhadas por todo o CPB, tornando possível sugerir que diferentes pulsos de magma, em diferentes áreas do maciço, possam ter acontecido em diferentes idades (mas não muito distanciadas temporalmente).

\section{Resultados Lu-Hf}

Foram selecionadas 6 amostras para análise pelo método Lu-Hf, buscando investigar pelo menos uma amostra representante de cada litologia/faciologia: GPB01 e GPB02 (Fácies Média-Homogênea); GPBB02 (Fácies Bandada); GPBH02 (Fácies Hololeucocrática); FAV01 e FAV02 (granito Favela).

Os processos de fusão parcial no manto modificaram os valores da razão $\mathrm{Lu} / \mathrm{Hf}$ ao longo do tempo, dando às rochas derivadas uma razão $\mathrm{Lu} / \mathrm{Hf}$ diferente da considerada inicial para o planeta (Kinny \& Maas, 2003). Essa diferença ocorre devido ao comportamento geoquímico dos elementos Lu e Hf: o Hf, em relação ao Lu, 


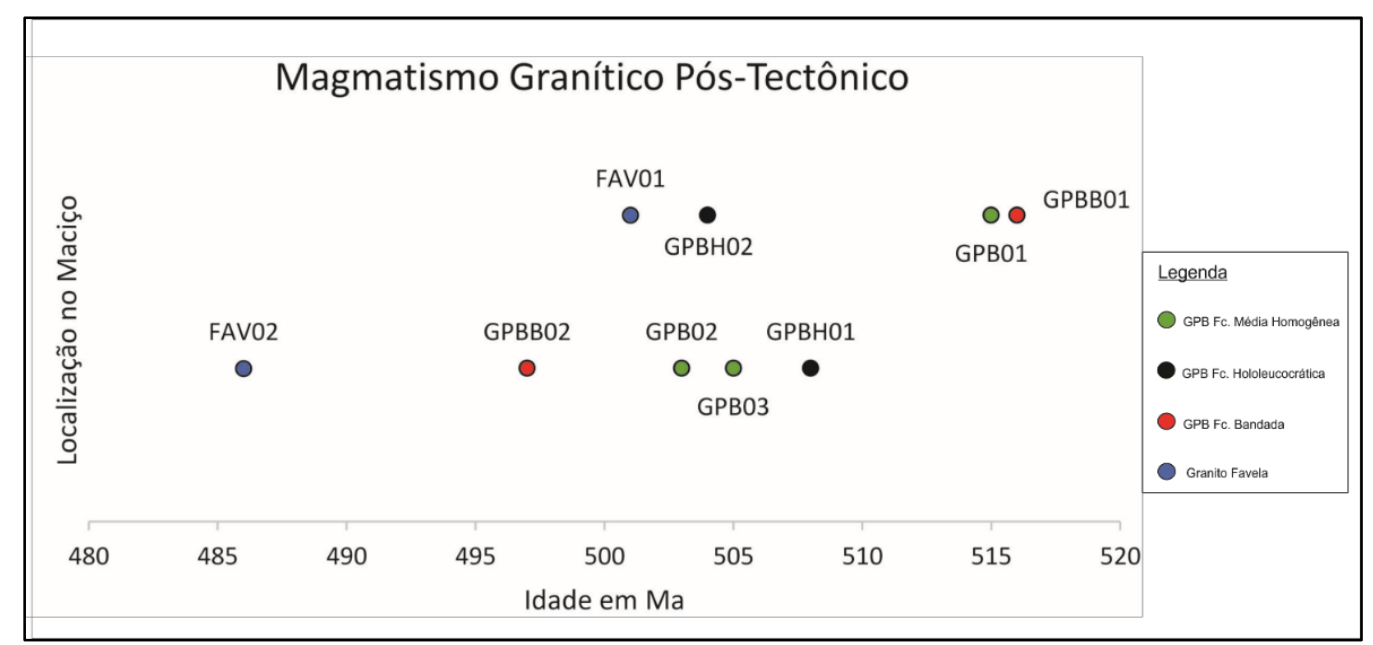

Figura 6: Relação entre as idades encontradas para as diferentes fácies do granito Pedra Branca e granito Favela e suas respectivas localizações no maciço, onde as superiores se referem à área situada mais a norte e as inferiores à região localizada a sul. Notar a proximidade e alternância entre os valores referentes às fácies (Fc.) Média Homogênea (GPB02 e GPB03) e Hololeucocrática (GPBH01 e GPBH02).

é mais incompatível, concentrando-se assim no líquido silicático durante a fusão parcial do manto, gerando assim um manto depletado (DM) em Hf e formando uma crosta mais enriquecida em Hf. Consequentemente, os magmas basálticos derivados do manto têm razões Lu/Hf mais baixas que a da rocha fonte (Faure \& Mensing, 2005). Sendo assim, comparando-se a razão ${ }^{176} \mathrm{Hf} /{ }^{177} \mathrm{Hf}$ da amostra estudada com o reservatório condrítico uniforme padrão (CHUR) se torna possível identificar sua fonte (manto ou crosta). Se a razão ${ }^{176} \mathrm{Hf} /{ }^{177} \mathrm{Hf}$ encontrada for mais elevada que a do condrito, então o parâmetro petrogenético $\varepsilon \mathrm{Hf}$ (partes por mil em relação ao valor do CHUR) será positivo, indicando que a fonte possuía razão $\mathrm{Lu} / \mathrm{Hf}$ superior à do condrito (fonte). Se a razão for menor, o $\varepsilon H f$ será negativo, indicando que o magma possui origem crustal (Machado \& Simonetti, 2001; Kinny \& Maas, 2003; Geraldes, 2010; Bertotti et al., 2013). Como a razão Lu/Hf apresentou variações significativas devido ao comportamento do Lu-Hf, este método, assim como o modelo Sm-Nd, permite o cálculo de idades modelo $\left(\mathrm{T}_{\mathrm{DM}}\right)$ baseadas na evolução isotópica do ${ }^{176} \mathrm{Lu}$. O cálculo indica o tempo decorrido desde a geração do grão, a partir de um magma com razão equivalente ao manto empobrecido (Geraldes, 2010).

Para análise do comportamento dos isótopos de Hf foram gerados gráficos (Figura 7) que relacionam o parâmetro petrogenético $\varepsilon \mathrm{Hf}$ com as idades obtidas pelo método U-Pb para cada amostra. Os valores dos isótopos encontrados para as amostras são comparados aos valores referentes ao reservatório condrítico uniforme padrão (CHUR) e ao manto depletado (Depleted Mantle-DM). Os dados utilizados na confecção dos gráficos encontram-se do Apêndice II

A Figura 8 resume os resultados dos indicadores $\varepsilon \mathrm{Hf}$ para as amostras estudadas. Os valores obtidos a partir do indicador petrogenético $\varepsilon \mathrm{Hf}$ indicaram bimodalidade nas fontes geradoras do CPB. As amostras GPB02, GPBB02 e FAV01 apresentaram valores de $\varepsilon \mathrm{Hf}$ majoritariamente positivos $(+0,8-+15,8)$, indicando fonte mantélica para o magmatismo, enquanto as amostras GPB01, GPBH02 e FAV02 exibiram valores majoritariamente negativos de $\varepsilon \mathrm{Hf}(-27$ - -2,8). O tempo de residência crustal foi superior nas amostras que apresentaram $\varepsilon \mathrm{Hf}$ negativo, com idades $\mathrm{T}_{\mathrm{DM}}$ maiores $(1,33-2,80$ Ma), em contraste com as amostras formadas através de fonte mantélica (0,53 - 1,66 Ma). De Campos et al. (2004), em estudo realizado na região norte da Faixa Ribeira, afirma que o magmatismo na área é produto de magmas oriundos de fontes crustais e mantélicas, sendo que a ascensão de magmas mantélicos através de zonas de cisalhamento, pode ter aumentado o gradiente termal e induzido fusões crustais. $\mathrm{O}$ mesmo pode ser observado para o CPB. Ainda que as diferentes fácies tenham sido produto de diferenciação magmática in situ, as diferentes fusões e misturas de fontes, como apresentado em Porto Jr (2004), bem como sua evolução até seu emplacement podem ter sido responsáveis pelos diferentes valores de $\varepsilon \mathrm{Hf}$.

A discussão apresentada por Porto Jr et al. (2018), a respeito da origem da fácies Hololeucocrática com formação associada a processos cumuláticos iniciais, causados pelo fluxo de 

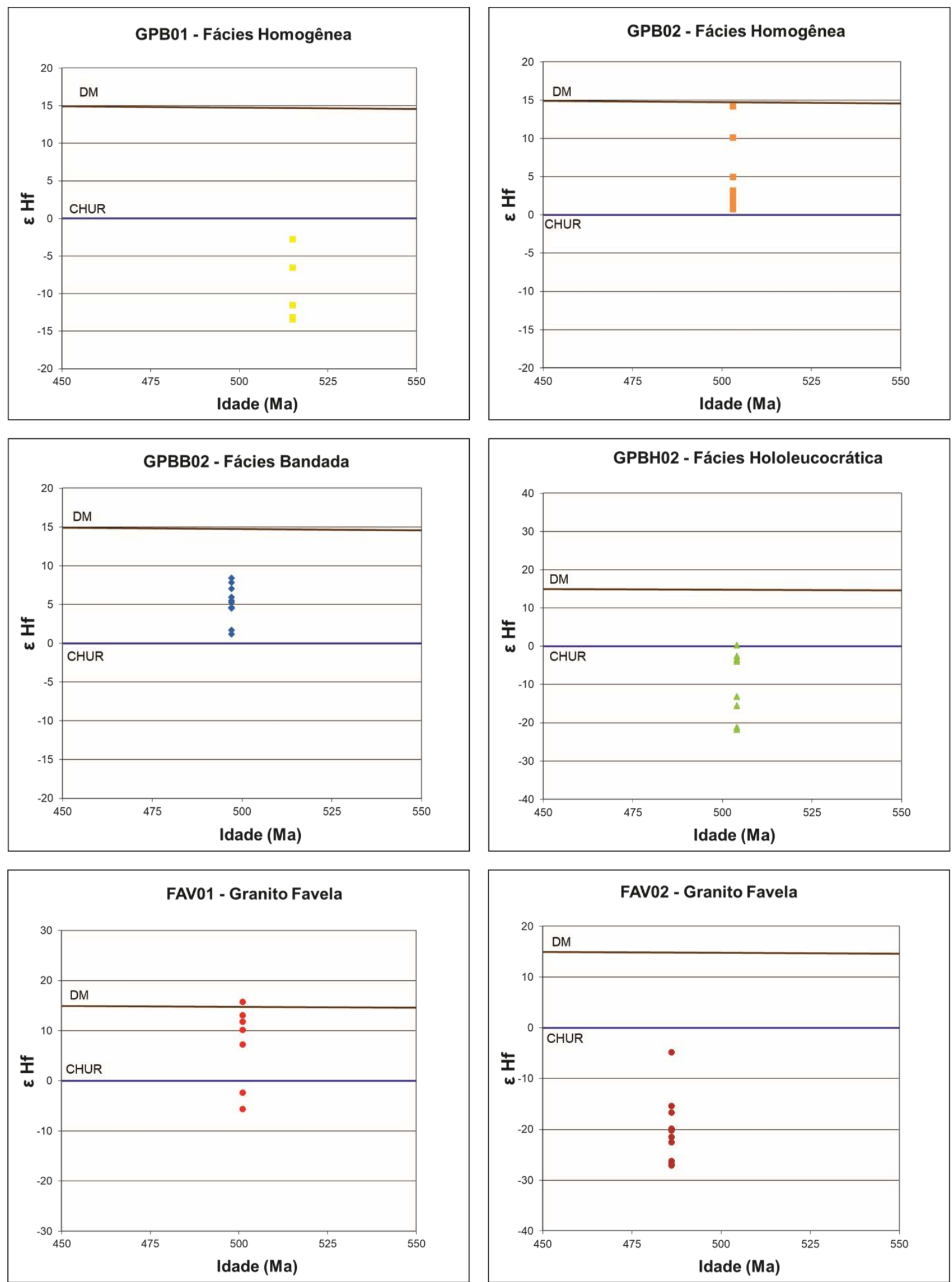

Figura 7: Gráficos utilizando o indicador $\varepsilon H f$ para definir a origem da fonte do magmatismo. Os resultados de $\varepsilon \mathrm{Hf}$ obtidos para as amostras GPB02, GPBB02 e FAV01 indicam que estas tiveram fonte mantélica, enquanto que para as amostras GPB01, GPBH02 e FAV02 tiveram fonte crustal. CHUR: $\varepsilon H f=0$; DM: $\varepsilon H f=14,7$. 


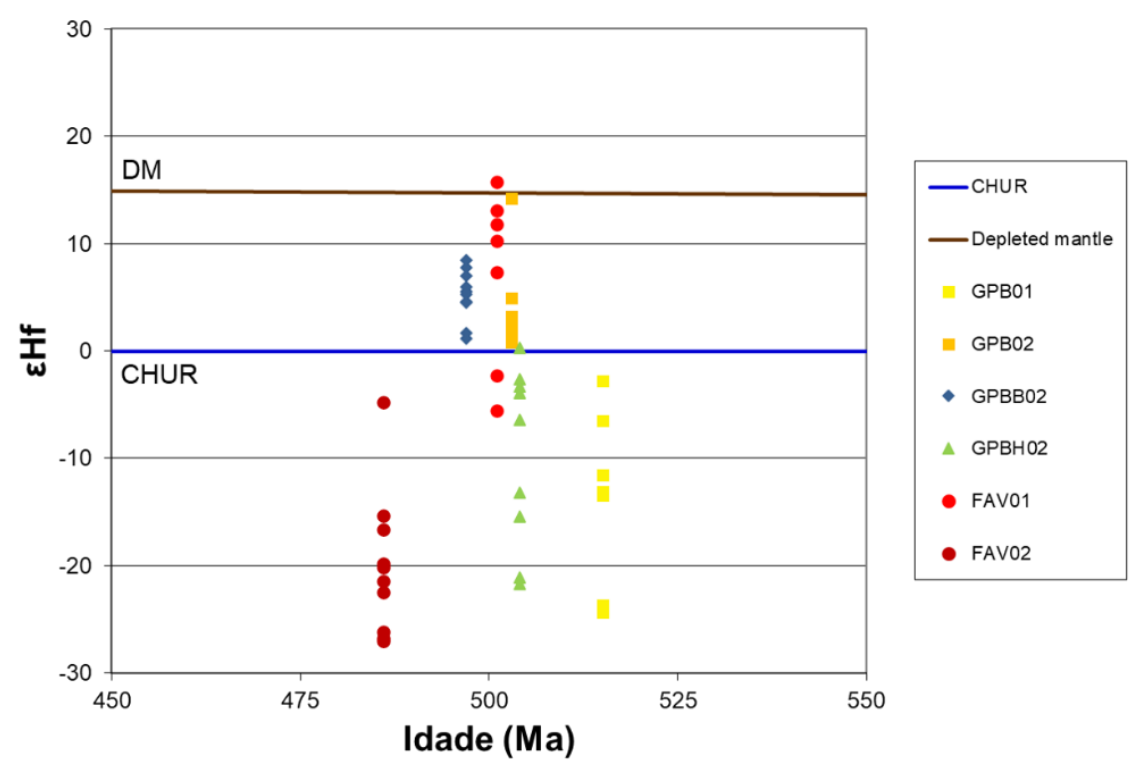

Figura 8: Resumo dos resultados dos indicadores $\varepsilon \mathrm{Hf}$ para as amostras estudadas do Complexo Pedra Branca.

magma próximo às paredes da rocha encaixante, $\varepsilon H f$ negativos. É possível ainda admitir que a somado à ascensão de líquido intersticial por diferenciação poderá ter ocorrido a partir de um filter pressing (Mckenzie, 1987), foi sustentada magma já contaminado. O processo inicial de pelos valores negativos $\varepsilon \mathrm{Hf}$ obtidos para a fusão poderá ter sido desencadeado pelo colapso amostra GPBH02. A proximidade da percolação da crosta espessa, devido à tectônica extensional de fluídos próximos à encaixante poderá ter atuante (Heilbron \& Machado, 2003) ou pela resultado na sua assimilação, diferenciando ainda quebra da litosfera oceânica subductada (Sölner mais o líquido residual e gerando os valores de et al., 1987, 2000).

\section{CONCLUSÃO}

Os dados obtidos nesta pesquisa permitiram aprofundar conhecimentos adquiridos em trabalhos anteriores sobre a origem e formação do CPB. As idades obtidas para o granito Pedra Branca (GPB01: 514,6 \pm 6,9 Ma, GPB02: 503,4 \pm 5,3 Ma, GPB03: 505,3 \pm 6,7 Ma, GPBB01: 516,3 \pm 7,8 Мa, GPBB02: 496,8 \pm 4,4 Ma, GPBH01: 507,7 \pm 5,6 Ma e GPBH02: $504 \mathrm{Ma}$ ) е para o granito Favela (FAV01: $501 \pm 3,6$ Ma e FAV02: $486 \pm$ 7,7 Ma ) indicaram que a atividade magmática representada pelo Complexo Pedra Branca aconteceu na forma de pulsos progressivos, com intervalos não muito longos entre si,

tornando o valor do intervalo médio entre os eventos menor para o Complexo ( 20 Ma). A fusão inicial, possivelmente ocasionada pela descompressão gerada pelo colapso do orógeno ou pela quebra da litosfera oceânica subductada, poderá ter contado com a participação de fontes mantélicas e crustais, dando caráter bimodal ao magmatismo, em relação ao indicador petrogenético $\varepsilon H f$. Através deste, também foi possível colocar a hipótese sobre a formação da fácies Hololeucocrática, que se terá diferenciado a partir de sua fácies “hospedeira”, a fácies MédiaHomogênea.

\section{AGRADECIMENTOS}

Ana Carolina Moterani agradece à CAPES pela bolsa de pesquisa concedida. Mauro Geraldes gostaria de agradecer ao Conselho Nacional de Desenvolvimento Científico e Tecnológico (CNPq) e à Fundação de Amparo à Pesquisa do Estado do Rio de Janeiro, FAPERJ pelas bolsas de pesquisa (processo $n^{0}$ 301470/2016-2 e E-26/202.843/2017, respectivamente). Virgínia Martins agradece ao CNPq e FAPERJ as bolsas de pesquisa (processo $n^{\circ} 302676 / 2019-8$ e processo $n^{0} 202.927 / 2019$, respectivamente).

\section{REFERÊNCIAS}

ALMEIDA, F.F.M.; AMARAL, G.; CORDANI, U.G.; KWASHITA, K. The Precambrian evolution of the South America cratonic margin south of Amazon River. In: NAIRN, A.E.M.; STEHLI, F.G.; UYEDA, S. (Eds), Ocean basins and

margins. N. York, Plenum. v. 1, p. 411-446, 1973.

ANDERSEN, T.; ANDERSSON, U.B.; GRAHAM, S.; ÅBERG, G.; SIMONSEN, S.L. Granitic magmatism by melting of juvenile continental crust: new constraints on the source of 
Palaeoproterozoic granitoids in Fennoscandia from Hf isotopes in zircon. Journal of the Geological Society. v. 166; p. 233 247, 2009.

BERTOTTI, A.L.; CHEMALE JR, F.; KAWASHITA, K. Lu-Hf em zircão por LA-MC-ICP-MS: aplicação em gabro do Ofiolito Aburrá, Colômbia. Pesquisas em Geociências, v. 40, n. 2, p. 117-127, 2013.

BOUVIER, A.; VERVOORT, J.D.; PATCHETT, P.J. The Lu-Hf and Sm-Nd isotopic composition of CHUR: Constraints from unequilibrated chondrites and implications for the bulk composition of terrestrial planets. Earth and Planetary Science Letters. v. 273, p. 48-57, 2008.

DE CAMPOS, C.P.; MENDES, J.C.; LUDKA, I.P., MEDEIROS, S.R.; MOURA, J.C.; WALLFASS, C. A review of the Brasiliano magmatism in Southern Espírito Santo, Brazil, with emphasis on post-collisional magmatism. ISSN 1441-8142. Journal of the Virtual Explorer, Electronic Edition v. 17 Paper 1, 2004.

ESTEVES, A. Mapeamento de detalhe, geologia estrutural e metamorfismo da região da Curicica, Jacarepaguá, Rio de Janeiro, RJ. Seropédica, 2002, 96p. Monografia de Graduação. GEP/UFRRJ.

FAURE, Gunter; MENSING, Teresa $M$. Principles and applications. John Wiley \& Sons, Inc, 2005.

GERALDES, M.C. Introdução à Geocronologia. Sociedade Brasileira de Geologia. 146p. 2010.

GRIFFIN, W.L.; PEARSON, N.J; BELOUSOVA, E.; JACKSON, S.E.; VAN ACHTERBERGH, E.; O’REILLY, S.Y.; SHEE, S.R. The Hf isotope composition of cratonic mantle: LAM-MC-ICPMS analysis of zircon megacrysts in kimberlites. Geochimica et Cosmochimica Acta. v. 64, p. 133-147, 2000.

HARLEY, S.; KELLY, N.; MOELLER, A. Zircon Behaviour and the Thermal Histories of Mountain Chains. Elements. 3. 25-30. 2007.

HASUI, Y. \& OLIVEIRA, M.A.F. Província Mantiqueira. Setor Central. In: ALMEIDA, FFM \& HASUI, Y. O PréCambriano do Brasil. Ed. Edgard Blucher. p. 308-344. São Paulo. 1984.

HEILBRON, M. \& MACHADO, N. Timing of terrane accretion in the Neoproterozoic-Eopaleozoic Ribeira orogen (SE Brasil). Precambrian Research, v. 125, p. 87-112, 2003.

HEILBRON, M.; PEDROSA-SOARES A.C.; CAMPOS NETO M.; SILVA L.C.; TROUW R.A.J. A Província Mantiqueira. In: MANTESSO NETO A., BARTORELLI A., CARNEIRO C.D.R., BRITO NEVES B.B. (eds.). O desvendar de um continente: a moderna geologia da América do Sul e o legado da obra de Fernando Flávio Marques de Almeida. São Paulo, Ed. Beca, p.203-234. 2004.

HEILBRON M.; MOHRIAK W.; VALERIANO C.M.; MILANI E.; ALMEIDA J.C.H.; TUPINAMBÁ M. From collision to extension: the roots of the south-eastern continental margin of Brazil. In: TALWANI \& MOHRIAK (eds) Atlantic Rifts and Continental Margins. American Geophysical Union, Geophysical Monograph Series, 115:1-34.2000.

HEILBRON, M.; TUPINAMBÁ, M.; VALERIANO, C.M.; ARMSTRONG, R.; SILVA, L.G.E.; MELO, R.S.; SIMONERRI, A.; MACHADO, N. The Serra da Bolívia Complex: the record of a new Neoproterozoic arc-related unit at the Ribeira belt. Precambrian Research. v. 50, p. 1-35, 2013.

HELMBOLD, R.; VALENÇA. J.G., LEONARDOS, Jr. O.H. Mapa geológico do Estado da Guanabara, esc. 1:50000. 3 Folhas. MME/DNPM. 1995.

LUDWIG, K. R. User's Manual for Isoplot 3.75-4.15. A Geochronological Toolkit Microsoft Excel. Berkeley Geochronology Center, Special Publication. 5, 75p, 2012

KINNY, P. D. \& MAAS, R. Lu-Hf and Sm-Nd isotope systems in zircon. Reviews in Mineralogy and Geochemistry. v 53, n 1, p. 327-341. 2003.

MACHADO, N. \& SIMONETTI, A. U-Pb dating and Hf isotopic composition of zircon by laser-ablation-MC-ICP-MS. Laser
ablation-ICPMS in the Earth sciences: Principles and applications, v. 29, p. 121-146, 2001.

MCKENZIE, D.P. The compaction of igneous and sedimentary rocks. Geol. Soc. London, v. 144, p. 299-307, 1987

NEBEL, O.; RAPP, R.P.; YAXLEY, G.M. The role of detrital zircons in Hadean crustal research. Lithos, v. 190, p. 313-327, 2014

NEBEL, O.; NEBEL-JACOBSEN, Y.; MEZGER, K.; BERNDT, J. Initial Hf isotope compositions in magmatic zircon from early Proterozoic rocks from the Gawler Craton, Australia: a test for zircon model ages. Chemical Geology, v. 241, n. 1-2, p. 23-37, 2007

PENHA, H.M. Geologia do Maciço da Pedra Branca, Rio de Janeiro, RJ. Anais da Academia Brasileira de Geociências. v. 53, n. 3, p. 355, 1984.

PENHA, H.M. \& WIEDEMANN, C.M. Granitoides da região central do Rio de Janeiro. In: CONGRESSO BRASILEIRO GEOLOGIA, 33, Rio de Janeiro, 1984. Roteiro de Excursões, p. 5433-5455.

PIRES, F.R.M.; VALENÇA, J.; RIBEIRO, A. Multistage generation of granite in Rio de Janeiro, Brazil. Anais da Academia Brasileira de Ciências v.54, p. 563-574, 1982.

PORTO JR., R. Considerações sobre a Petrogênese das Rochas Graníticas do Complexo Granítico Pedra Branca, Rio de Janeiro, Brasil. Publicação Especial dos Anais da Acad. Bras. de Ciências. Workshop MAGMA. P: 63-66. Rio de Janeiro. 1993.

PORTO JR. R. Petrologia das Rochas Graníticas das Serras de Pedra Branca e Misericórdia, Município do Rio de Janeiro, RJ, Brasil. Rio de Janeiro, 1994, 222p. Dissertação (Mestrado), Universidade Federal do Rio de Janeiro.

PORTO JR, R. Petrogênese das Rochas do Maciço da Pedra Branca. Rio de Janeiro, RJ. Rio de Janeiro, 2004. 283p. Tese (Doutorado), Universidade Federal do Rio de Janeiro.

PORTO JR., R. \& ESTEVES, A. Geological Characteristics of Gneisses at the Pedra Branca Granite Complex, Ribeira Belt, Rio de Janeiro, Brazil. In: EUROPEAN UNION GEOSCIENCES. 2001. Extend Abstracts: 228.

PORTO JR, R. \& VALENTE, S.V. As rochas granitoides do norte da Serra da Pedra Branca e suas relações com as encaixantes gnáissicas na região de Bangu, Rio de Janeiro, RJ. In: CONGRESSO BRASILEIRO DE GEOLOGIA, 35, 1988, Belém. Anais... Belém: SBG, 1988, v. 3, p. 1066-1079.

PORTO JR, R.; TESSER, L.R.; DUARTE, B.P. A origem do acamamento magmático no granito Pedra Branca, Maciço da Pedra Branca, Rio de Janeiro, Brasil. São Paulo, UNESP, Geociências, v. 37, n. 2, p. 237-251, 2018.

PORTO JR., R.; VALENTE, S.C.; DUARTE, B.P. Aspectos de Campo, Petrográficos e Geoquímicos de Acamamento Magmático de Granito do Complexo Granítico Pedra Branca, Rio de Janeiro, RJ, Brasil. CONGRESSO INTERNACIONAL DE GEOQUÍMICA DOS PAÍSES DE LÍNGUA PORTUGUESA, 1993, Porto, Portugal. Anais... Memórias (3) p: $150-154$.

PORTO JR., R.; VALENTE, S.C.; DUARTE, B.P. Geology of the Pedra Branca Massif, Rio de Janeiro, Brasil. In: $36^{\mathrm{TH}}$ INTERNATIONAL. GEOLOGICAL. CONGRESS. Extend Abstract..., Kyoto, Japão. 1992a.

PORTO JR., R.; VALENTE, S.C.; DUARTE, B.P. Caracterização do magmatismo Brasiliano no Paleozoico Inferior: o exemplo do pluton Pedra Branca. In: RABANO, I \& GUTIERREZ MARCO, JC. (Eds). Res. Conf. Intern. Paleoz. Inf. Ibero-Amer. Publ. Museu Geol. Extrem., v1 p, 123-124. $1992 b$.

SÖDERLUND, U; PATCHETT, J.P.; VERVOORT, J.D.; ISACHSEN, C.E. The 176Lu decay constant determined by $\mathrm{Lu}-\mathrm{Hf}$ and U-Pb isotope systematics of Precambrian mafic intrusions. Earth and Planetary Science Letters. v. 219 p.311-324, 2004.

SÖLNER, F.; LAMMERER, B.; WIEDEMANNLEONARDOS, C. Dating the Ribeira mobile belt of Brazil. Zeitschrift für angewandte Geologie, p. 245-255, 2000. 
SÖLNER, F.; LAMMERER, B.; WEBER-DIEFENBACH, K.; HANSEN, B.T. The Brasiliano Orogenesis: Age determinations (Rb-Sr and $\mathrm{U}-\mathrm{Pb}$ ) in the coastal mountain region of Espirito Santo, Brazil. Zentralblatt für Geologie und Paläontologie, Teil I, v. 7, n. 8, p. 729-741, 1987.

TUPINAMBÁ, M.; TEIXEIRA, W.; HEILBRON, M. Neoproterozoic Western Gondwana assembly and subductionrelated plutonism: the role of the Rio Negro Complex in the Ribeira Belt, Southeastern Brazil. Revista Brasileira de Geociências. v. 30 p. 7-11, 2000.

TUPINAMBÁ, M.; HEILBRON, M.; TEIXEIRA, W. Evolução Tectônica e Magmática da Faixa Ribeira entre o neoproterozoico e o paleozoico inferior na Região Serrana do Estado do Rio de Janeiro, Brasil. Anuário do Instituto de Geociências. v. 35, p. 140-151, 2013.

TUPINAMBÁ, M.; HEILBRON, M.; OLIVEIRA, A.; PEREIRA, A.J.; CUNHA, E.R.S.P.; FERNANDES, G.A.; FERREIRA, J.; CASTILHO, G.; TEIXEIRA, W. Complexo Rio Negro - uma unidade estratigráfica relevante no entendimento da evolução da Faixa Ribeira. In: CONGRESSO BRASILEIRO DE GEOLOGIA, 39, Salvador. Anais... Salvador: SBG, 1996, v.6, p. 104-106.

TUPINAMBÁ, M.; HEILBRON, M.; DUARTE, B.P.; NOGUEIRA, J.R.; VALLADARES, C.; ALMEIDA, J.; EIRADO SILVA, L.G.; MEDEIROS, S.R.; ALMEIDA, C.G.; MIRANDA, A.; RAGATKY, C.D.; MENDES, J.; LUDKA, I. Geologia da Faixa Ribeira Setentrional: estado da arte e conexões com a Faixa Araçuaí. Geonomos, v. 15, n.1, p. 67-79, 2007.

TROUW, R.A.J.; HEILBRON, M.; RIBEIRO, A.; PACIULLO, F.V.P.; VALERIANO, C.M.; ALMEIDA, J.C.H.; TUPINAMBÁ, M.; ANDREIS, R.R. The central segment of the Ribeira Belt. In: U.G. CORDANI, E.J. MILANI, A. Tectonic Evolution of South America. Rio de Janeiro, Thomaz Filho (eds.), p. 287-310. 2000.
TROUW, R.A.J.; PETERNEL, R.; RIBEIRO, A.; HEILBRON, M.; VINAGRE, R.; DUFFLES, P.; TROUW, C.; FONTAINHA, M.; KUSSAMA, H.H. A new interpretation for the interference zone between the southern Brasília belt and the central Ribeira belt, SE Brazil. Journal of South American Earth Sciences. v. 48, p. 43-57, 2013

VALERIANO, C.M.; MENDES, J.C.; TUPINAMBÁ, M.; BONGIOLO, E.; HEILBRON, M.; JUNHO, M.C.B. CambroOrdovician post-collisional granites of the Ribeira Belt, SEBrasil: A case of terminal magmatism of a hot orogen. Journal of South American Earth Sciences v. 68, p.269-281, 2016.

VALERIANO, C.M.; TUPINAMBÁ, M.; SIMONETTI, A.; HEILBRON, M.; ALMEIDA, J.C.H.; EIRADO, L. G. U-Pb LA-MC-ICPMS geochronology of Cambro-Ordovician postcollisional granites of the Ribeira belt, southeast Brazil: Terminal Brasiliano magmatism in central Gondwana supercontinent. Journal of South American Earth Sciences, v. 32, p. 416-428, 2011.

VIGNERESSE, J.L.; BARBEY, P. \& CUNEY, N. Rheological Transitions During Partial Melting and Crystallization with Application to Felsic Magma Segregation and Transfer. Journal of Petrology, v. 37, p. 1579-1600, 1996.

Submetido em 27 de agosto de 2019 Aceito para publicação em 8 de dezembro de 2020 


\section{ANEXO 1:}

Imagens dos epóxis contendo os grãos de zircão coletados para cada amostra, separados de acordo com suas respectivas suscetibilidades magnéticas (5 - NA (Não atraída).
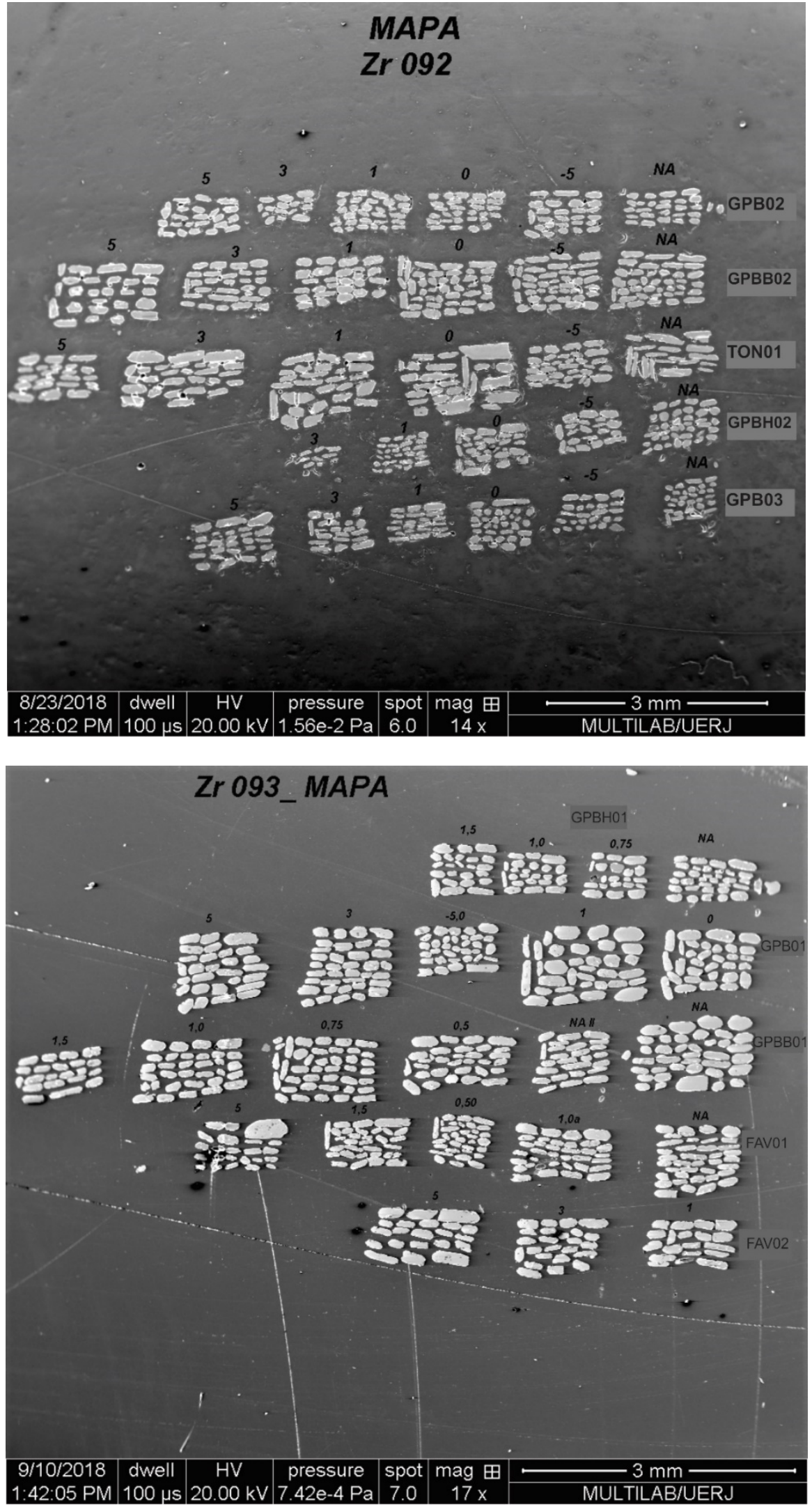


\section{APÊNDICE I:}

Resultado das análises U-Pb por LA-ICP-MC-MS para todas as amostras. Os dados exibidos foram os utilizados para confecção dos Diagramas Concórdia para cada amostra.

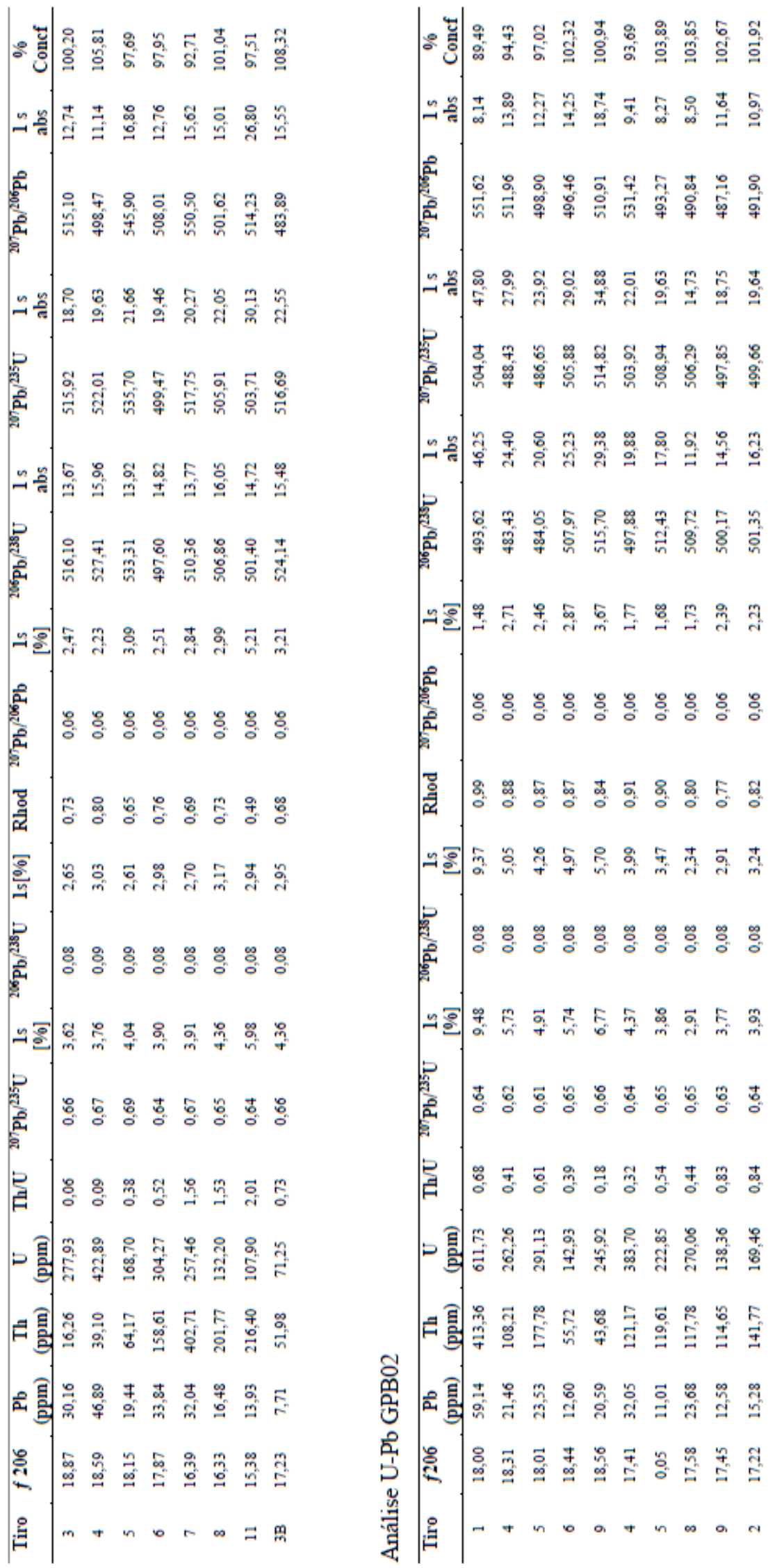




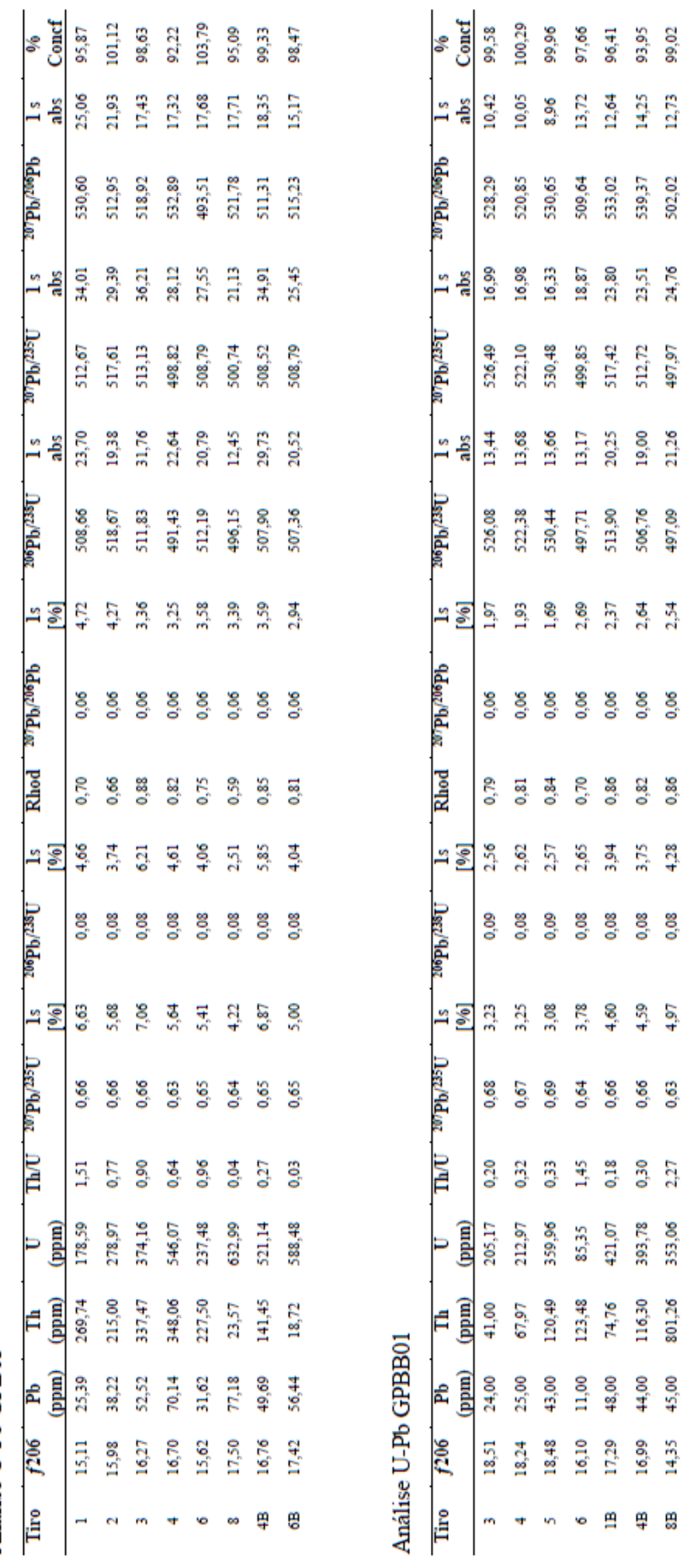




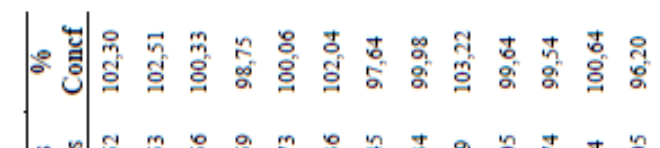

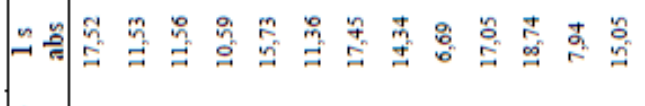

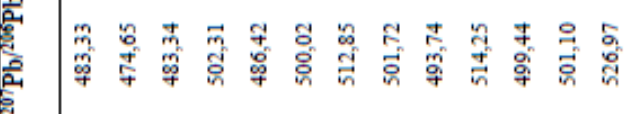

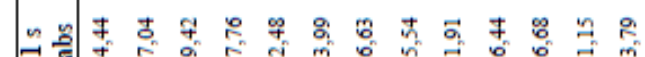

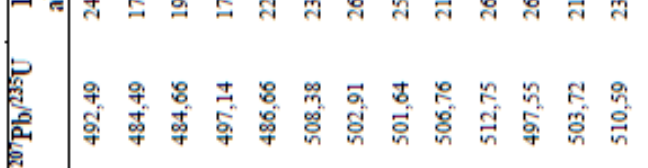

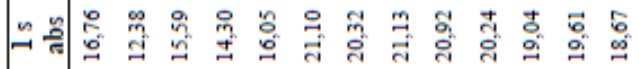

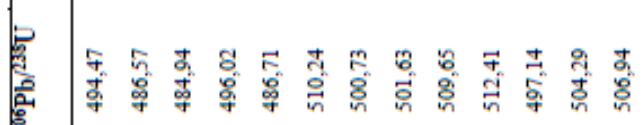

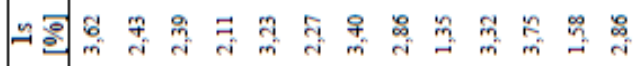

焉

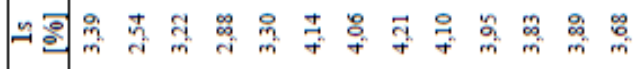

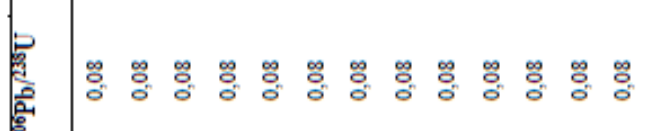

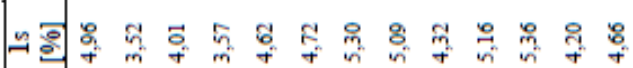

宏

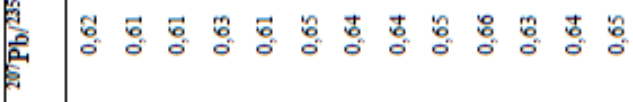

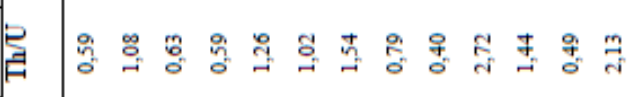

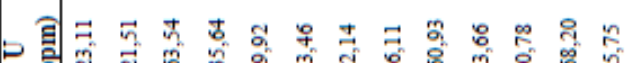

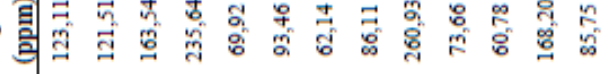

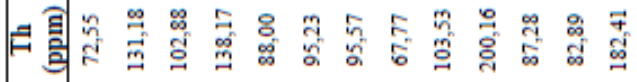

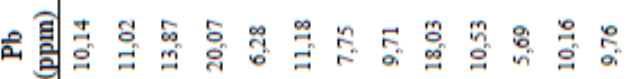

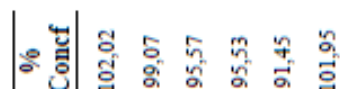

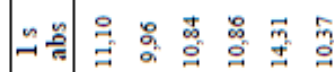

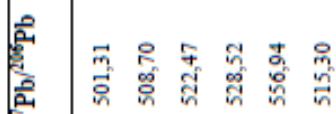

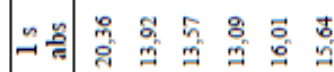

绝

๘

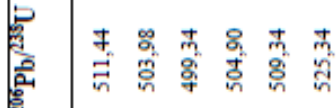

๓옹

숭

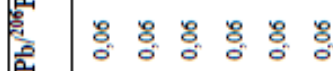

길

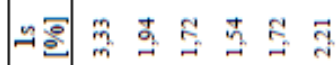

点

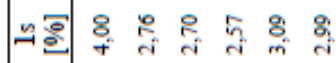

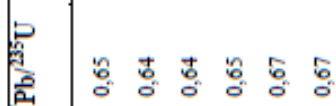

격 동 홍 웡 정 경 형

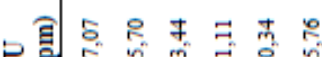

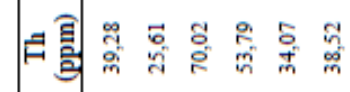

䈏

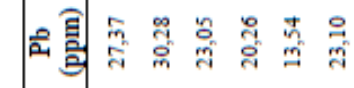

棼

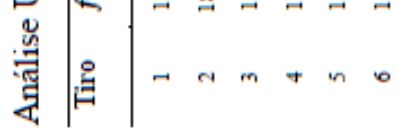




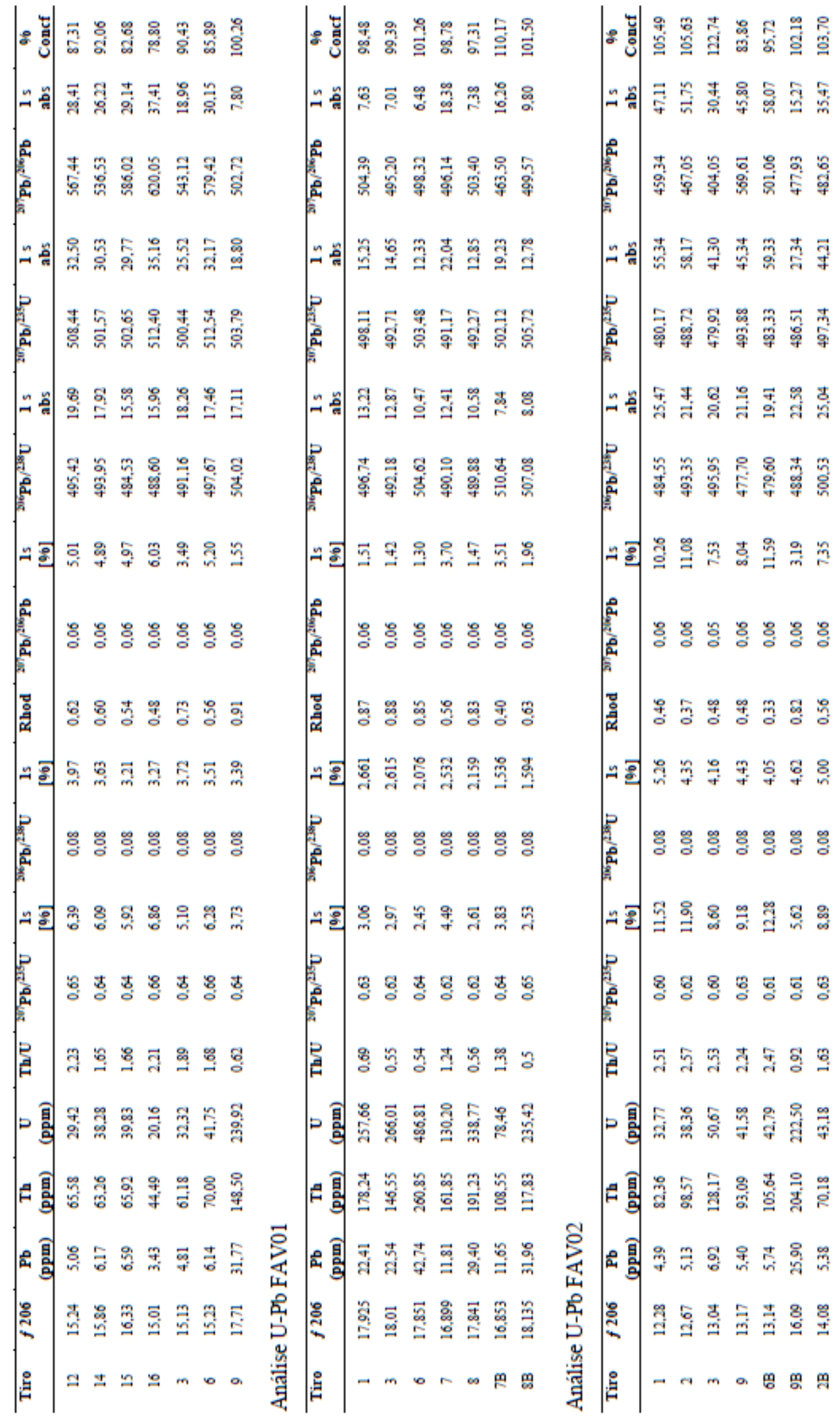




\section{APÊNDICE II:}

Resultado das análises Lu-Hf para as amostras GPB01, GPB01, GPBB02, GPBH02, FAV01 E FAV02.

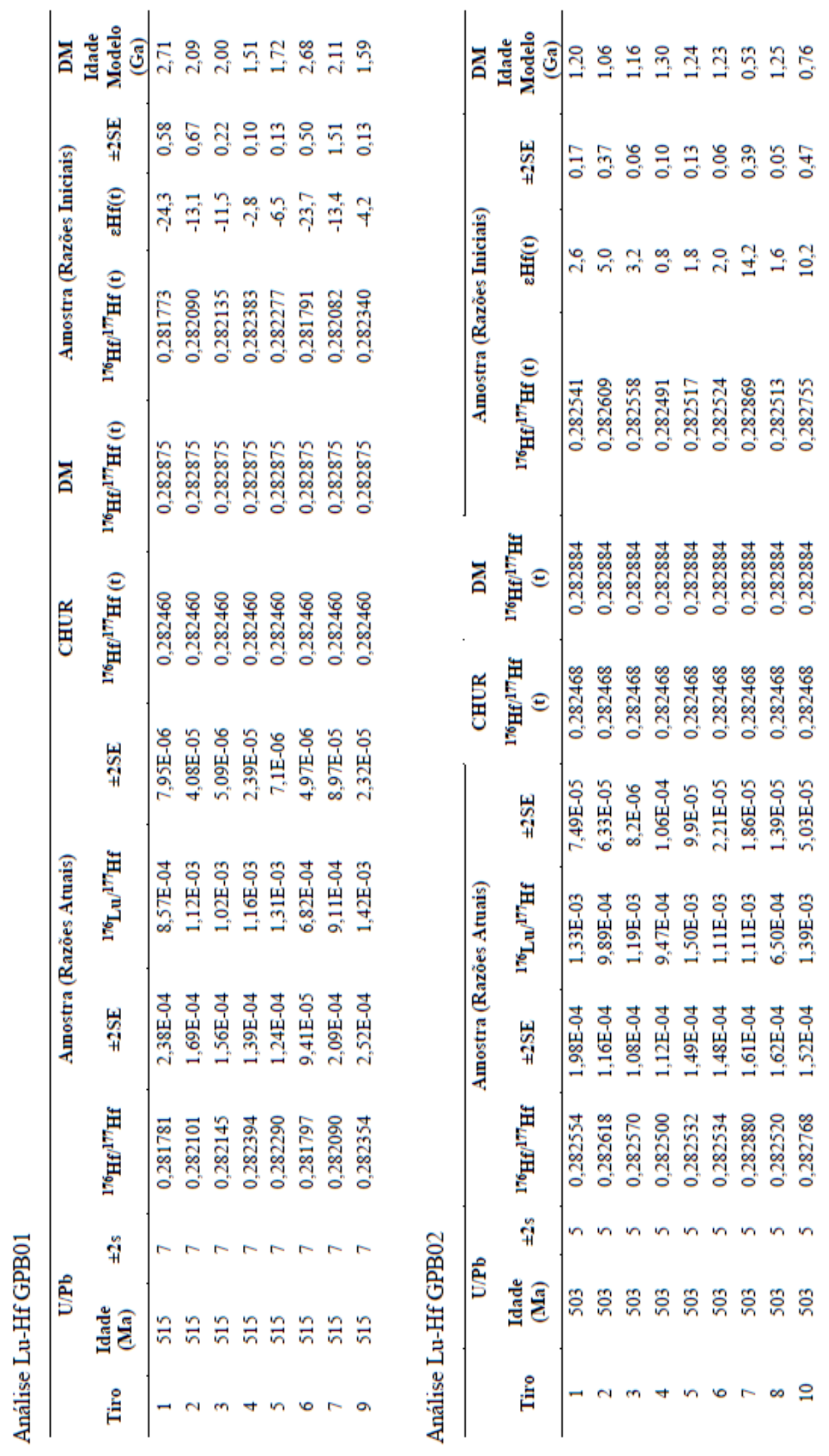




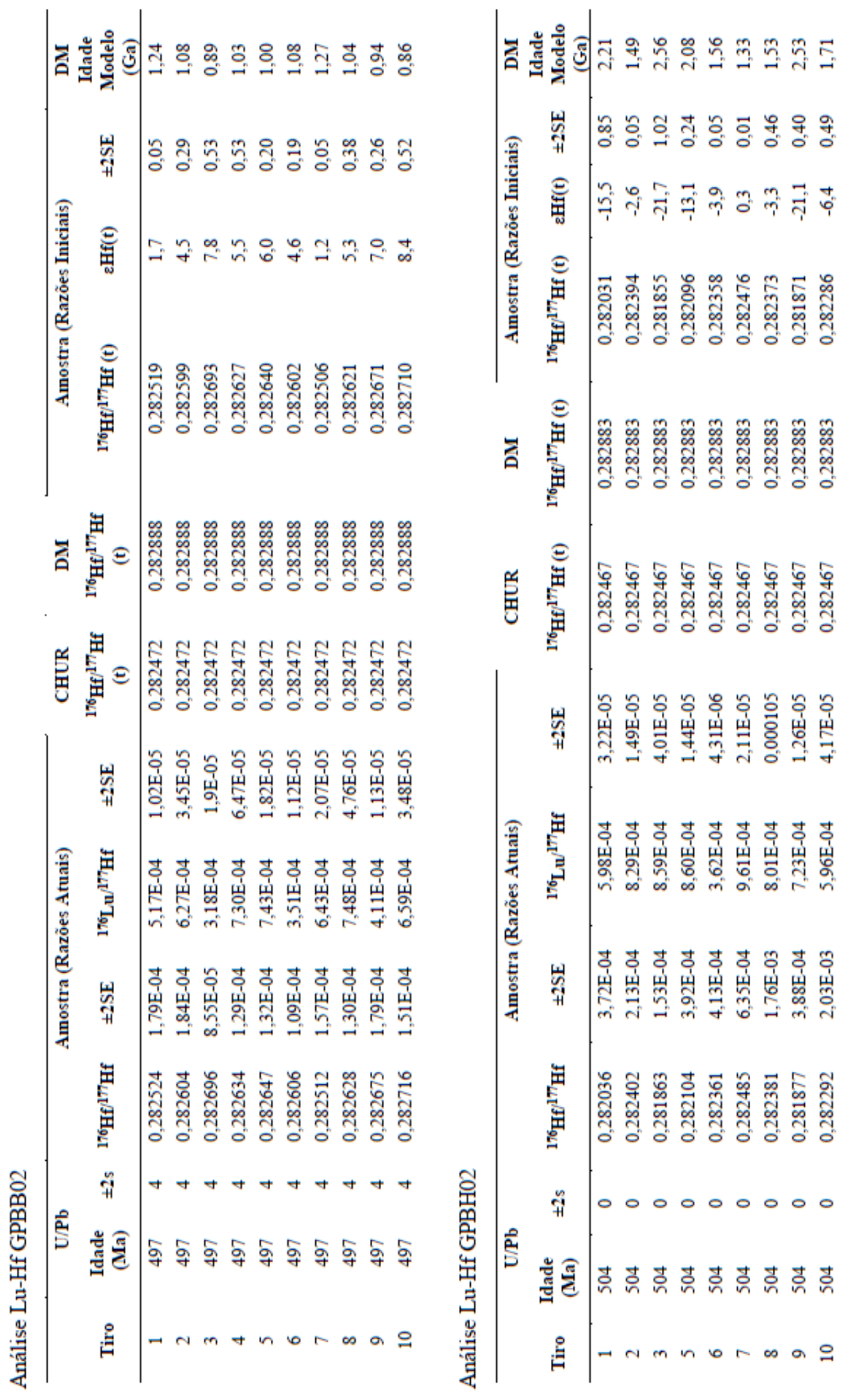




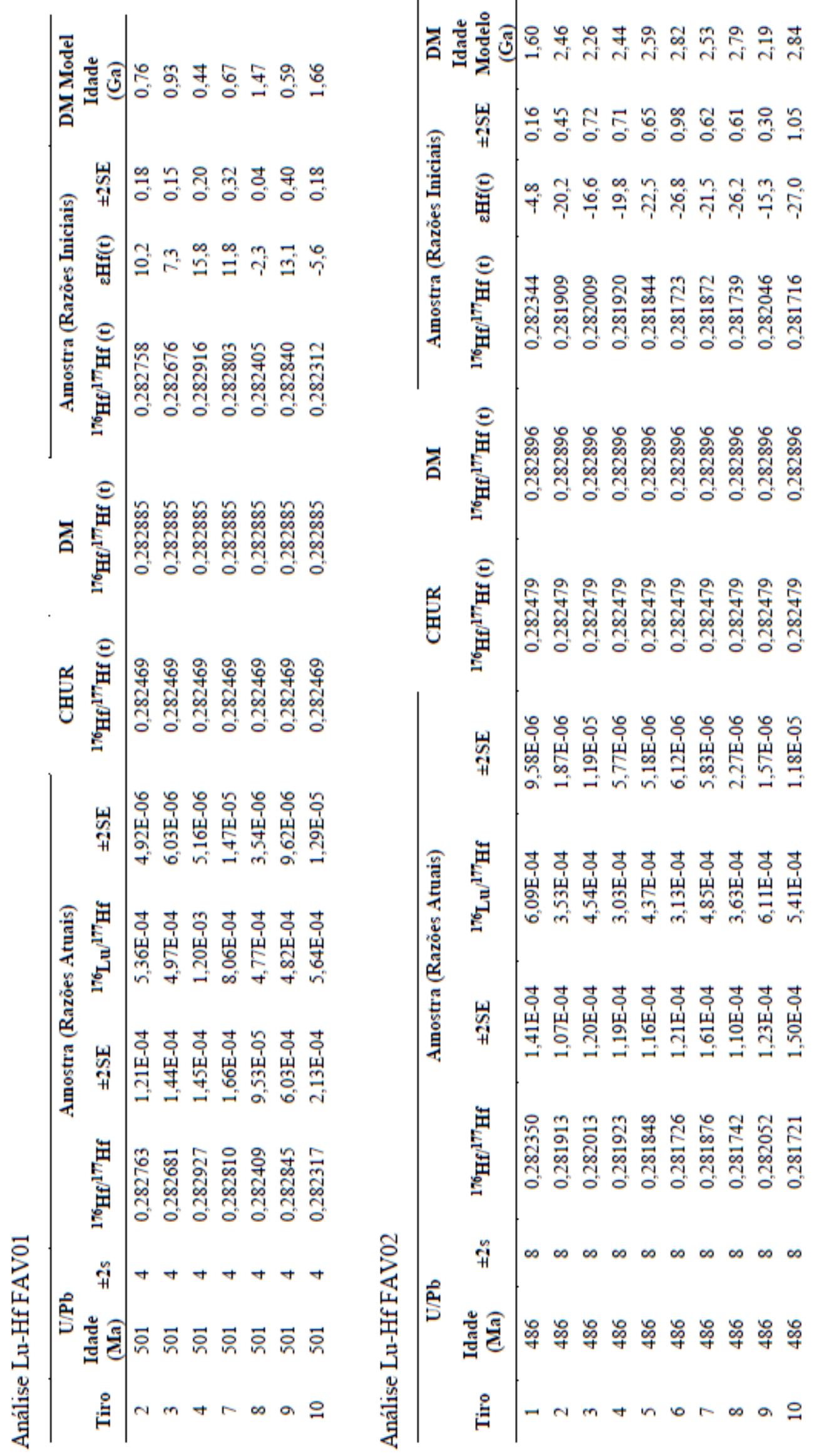

